The FASEB Journal express article 10.1096/fj.04-2285fje. Published online September 23, 2004.

\title{
Activation of p38 MAPK is required for Bax translocation to mitochondria, cytochrome $c$ release and apoptosis induced by UVB irradiation in human keratinocytes
}

An Van Laethem, ${ }^{* \dagger}$ Sofie Van Kelst, ${ }^{*},{ }^{\dagger}$ Saskia Lippens, ${ }^{\star}$ Wim Declercq, ${ }^{\star}$ Peter Vandenabeele, ${ }^{*}$ Stefan Janssens, ${ }^{\S}$ Jackie R. Vandenheede, ${ }^{*}$ Maria Garmyn, ${ }^{\dagger}$ and Patrizia Agostinis*

*Division of Biochemistry and ${ }^{\dagger}$ Laboratory of Dermatology, Catholic University of Leuven, Belgium; ${ }^{\ddagger}$ Department for Molecular Biomedical Research, Flanders Interuniversity Institute for Biotechnology, University of Ghent, Belgium; and ${ }^{\S}$ Department of Cardiology Faculty of Medicine, Catholic University of Leuven, Belgium

Corresponding author: Division of Biochemistry, Herestraat 49, B-3000, Leuven, Belgium. Email: patricia.agostinis@med.kuleuven.ac.be

\section{ABSTRACT}

This study establishes that activation of p38 MAPK by UVB represents a crucial signal required for the conformational change and translocation of Bax to the mitochondria in human keratinocytes. UVB-induced Bax translocation and mitochondrial cytochrome $c$ release, which precede caspase activation and other endpoints of the apoptotic program such as chromatin fragmentation and loss of mitochondrial transmembrane potential, are blocked by genetic or pharmacological inhibition of the p38 $\alpha$ MAPK. Inhibition of p38 MAPK strongly reduces the UVB-induced formation of sunburn cells and blocks Bax conformational change both in cultured human keratinocytes and in human skin, providing clear evidence for the physiological role of the p38 MAPK-Bax pathway in the removal of precancerous, UVB-damaged keratinocytes. Furthermore, we show that Bcl-2 overexpression, but not the pan-caspase inhibitor zVAD-fmk, blocks Bax conformational change and its subsequent translocation downstream of p38 MAPK. These data indicate that the activation of p38 MAPK by UVB engages a caspase-independent death signal leading to mitochondrial membrane permeabilization and apoptosis in human keratinocytes and suggest that p38 MAPK might have a preventive role in the process of photocarcinogenesis.

Key words: skin equivalents $\bullet$ skin organ cultures $\bullet$ photocarcinogenesis $\bullet$ HaCaT cells

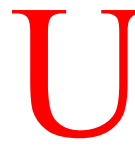

VB-induced apoptosis entails a complex network of signaling pathways activated in response to DNA damage, receptor clustering, and production of reactive oxygen species, ultimately converging into the activation of caspases, which are the final executioners of UVB-induced cell death (1). In vivo, this fail-safe program is revealed by the appearance of sunburn cells, which represent irreversibly damaged keratinocytes undergoing apoptosis (2). Although p53 is a critical mediator of the UV-induced apoptotic response (3), additional pathways must exist since cells expressing mutated p53 or cells that are deficient in 
p53 can still undergo apoptosis in response to UVB, albeit with a lesser efficiency (4-7). The identification of the mechanisms ensuring death of the UV-damaged keratinocytes is of therapeutic relevance, since it may provide the molecular bases to devise interventional strategies for the treatment of skin tumors in which p53 is frequently mutated.

Recent studies indicate that the mitochondria play a pivotal role as integrating sensors and endpoints of different signaling pathways participating in the complex UVB-induced apoptotic program. The mitochondrial pathway of apoptosis is triggered by the cytochrome $c$-mediated formation of the "apoptosome", the heptameric platform formed in the presence of ATP by Apaf- 1 and cytochrome $c$, which recruits procaspase- 9 and leads to its activation $(8,9)$.

Sitailo and co-workers have shown that in human keratinocytes caspase 9 is the dominant apical caspase in the UVB-induced death cascade (10). Consistent with this notion, overexpression of powerful inhibitors of the mitochondrial pathway of apoptosis, such as $b c l-2$ or $b c l-\mathrm{X}_{\mathrm{L}}(11-16)$ as well as of the inhibitor of apoptosis (IAP) member survivin (17), has been shown to effectively protect keratinocytes from UVB-induced killing and increase skin tumor formation in transgenic mice.

In several apoptotic paradigms the permeabilization of the mitochondrial membranes, releasing cytochrome $c$ into the cytosol, requires the action of pro-apoptotic Bcl-2 family members. During apoptosis induced by different cellular stresses the conformational change and redistribution of Bax from the cytoplasm to the outer mitochondrial membrane represents the necessary endpoint, ensuring the release of cytochrome $c(18,19)$. Although some studies have used UV as a cellular DNA damaging agent to demonstrate the requirement of Bax for apoptosis, in most cases germicidal UVC light and cells others than the physiological targets, e.g., keratinocytes, have been used.

Hence, in spite of accumulating evidences for the crucial role of the mitochondrion-dependent death pathway in UV-induced apoptosis, the biochemical mechanisms controlling the mitochondrial release of cytochrome $c$ in human keratinocytes and their relevance for skin carcinogenesis, is far from being understood.

UVB is a potent activator of the JNK and p38 MAPK members of the MAPK superfamily, both in cultured keratinocytes and in human skin (20-22). Previous studies have suggested a role for p38 MAPK in the induction of apoptosis in UVB-irradiated keratinocytes $(4,23)$. However the mechanism by which $\mathrm{p} 38$ MAPK exerts this apoptogenic function remains to be unraveled.

In this study we show that the activation of p38 MAPK in response to UVB irradiation of human keratinocytes is critically required to promote, in a caspase-independent fashion, the redistribution of Bax from the cytosol to the mitochondria, which leads to cytochrome $c$ release and effector caspase activation. This UVB-induced death signal is overruled downstream of $\mathrm{p} 38$ MAPK activation by Bcl-2 overexpression, which blocks Bax translocation and subsequent postmitochondrial events precipitating keratinocyte apoptosis. The requirement of p38 MAPK for Bax translocation is reconstituted in skin organ cultures. Hence, p38 MAPK, by inducing the targeting of Bax to the mitochondria leading to cytochrome $c$ release and caspase activation, ensures the death of the UVB-damaged keratinocytes and could play a key role in protecting skin against photocarcinogenesis. 


\section{MATERIALS AND METHODS}

\section{Reagents and antibodies}

Polyclonal anti-p38 MAPK and -phosphospecific-p38 MAPK antibodies, recognizing the double phosphorylated (Thr180/Tyr182) and active form of the protein, were purchased from Cell Signaling (Beverly, MA). The p38 MAPK antibody for immunoprecipitation was from SanverTech. N-terminal Bax antibody, recognizing the active conformation of Bax was from Upstate Biotechnology (Lake Placid, NY). Anti-Bcl-2 was from PharMingen (San Diego, CA), anti-Poly (ADP-ribose) polymerase antibody and anti-Caspase-3 antibody were from Biomol (Plymouth Meeting, PA). Antibody against the cleaved form of caspase-3 for immunohistochemstry was from Cell Signaling. Texas Red ${ }^{\circledR}$ goat anti-rabbit IgG, Alexa Fluor goat anti-rabbit 488, and MitoTrackerRed CMXRos were from Molecular Probes (Eugene, OR, USA). Streptolysin O was purchased from Sigma (St. Louis, MO). The p38 MAPK inhibitors PD 169316 and SB 203580 were obtained from Alexis (Lausen, Switzerland). The pan-caspase inhibitor Z-Val-Ala-DL-Asp-fluoromethylketone (zVAD-fmk) was from Bachem (Bubendorf, Switzerland). G418 Sulfate was purchased from Calbiochem (San Diego, CA). DiOC 6 was purchased from Molecular Probes.

\section{Cell lines and culture conditions}

The spontaneously immortalized human keratinocyte cell line HaCaT was maintained in culture as already described $(4,11)$. In case of the HaCaT cell lines, stably overexpressing Bcl-2 (kindly supplied by R. Polakowska, Lille, France) or the DRp38 $\alpha$ MAPK mutant G418 sulfate ( $1 \mathrm{mg} / \mathrm{ml})$ was added to the culture medium. Primary keratinocytes were derived from foreskins of young donors (less than 6 years) as described previously (24). The DRp38 $\alpha$ MAPK mutant (Thr106Met, His107Pro, and Leu108Phe) was transfected into HaCaT cells via electroporation with a Nucleofector system from Amaxa Biosystems (Koeln, Germany). Twenty-four hours after transfection, G418 (1 $\mathrm{mg} / \mathrm{ml})$ was added to the culture medium to select the positive cells containing the mutant. A clone was grown from a single positive cell. Protein expression was detected on a Western blot. Skin equivalents were generated and cultured as already described (25). Skin organ cultures were derived from foreskin of a 1-year-old child, kept in culture in supplemented Keratinocyte-SFM medium and treated on the day of arrival. All cell lines were incubated in a $37^{\circ} \mathrm{C}$ humidified air environment containing $5 \% \mathrm{CO}_{2}$.

\section{UVB irradiation}

UVB irradiation was performed according to Assefa et al. (11). For irradiation of the skin equivalents or skin organ cultures, the filter inserts were placed on a sterile Petri dish. All the drugs used in this study were added to the culture medium prior to irradiation for the period of time indicated in the figure legends.

\section{Generation of Adenovirus carrying dominant negative p38 MAPK mutant}

Adenoviral (Ad) dominant negative (DN) p38 $\alpha$ MAPK (Thr180Ala and Tyr182Phe) was constructed according to the pAdEasy protocol (26). 


\section{Western blot analysis}

Whole cell lysates were obtained as described previously (27). Cellular fractionation to obtain cytosolic and particulate fractions was performed as described in (28). To obtain lysates from skin equivalents (SE) the epidermal sheets were left in HEPES buffer overnight at $-20 \mathrm{C}^{\circ}$. The following day the SE were sonicated $3 \times 20 \mathrm{~s}$ with a Bioruptor Sonicator from Cosmo Bio (Tokyo, Japan) and afterwards vortexed $30 \mathrm{~min}$ at $4 \mathrm{C}^{\circ}$. After centrifugation, supernatants were collected. Protein concentration of the resulting cell extracts was estimated with BCA (Pierce Rockford, IL). Western blot and detection of protein were performed as done previously (27).

\section{In vitro kinase assay}

Protein kinase assay was performed using a GST-ATF2 fusion protein as the substrate. p38 MAPK was immunoprecipitated from UVB irradiated as well as untreated lysates using $1 \mu \mathrm{g}$ of antibody per sample. Immune complexes were subsequently bound to protein A-sepharose beads. After washing three times in washing buffer (1\% NP-40, $2 \mathrm{mM} \mathrm{Na}_{3} \mathrm{VO}_{4}$ in PBS) and once in kinase buffer $\left(20 \mathrm{mM}\right.$ HEPES, $\mathrm{pH} 7.6 ; 15 \mathrm{mM} \mathrm{MgCl}_{2} ; 20 \mathrm{mM} \beta$-glycerophosphate; $2 \mathrm{mM}$ DTT; $0.1 \%$ Tritonx-100; $200 \mu \mathrm{M} \mathrm{Na} \mathrm{VO}_{4}$ ), the beads were pelleted and incubated with a substrate mix containing $3 \mu \mathrm{g}$ of GST-ATF2, $20 \mu \mathrm{M}$ ATP, $0.3 \mu \mathrm{Ci}\left[\gamma_{-}{ }^{32} \mathrm{P}\right]$ ATP in a volume of $30 \mu \mathrm{l}$ for $20 \mathrm{~min}$ at $37^{\circ} \mathrm{C}$. Afterwards the samples were boiled and separated on a $12.5 \% \mathrm{SDS}$ polyacrylamide gel. The gel was dried, and phosphorylation of GST-ATF2 determined by autoradiography.

\section{Measurement of mitochondrial transmembrane potential}

To measure the mitochondrial transmembrane potential, the cells were trypsinized at the indicated times after UVB treatment and incubated with $30 \mathrm{nM} \mathrm{DiOC}_{6}$ under dark conditions for $15 \mathrm{~min}$ at $37^{\circ} \mathrm{C}$. Fluorescence of the samples was subsequently measured by flow cytometry (FACScan, Beckton Dickinson), and data were analyzed using CellQuest (BD Biosciences, Canada) software.

\section{Histology and immunocytochemistry}

After treatment and incubation period as specified in the figure legends, the cells were fixed in $4 \%$ (v/v) formaldehyde in PBS for $30 \mathrm{~min}$ followed by another $30 \mathrm{~min}$ of permeabilization in ice-cold methanol. After washing, the cells were blocked for three hours in 1\% BSA in PBS. Then the first antibody, diluted in $1 \%$ BSA in PBS, was added and incubated overnight at $4{ }^{\circ} \mathrm{C}$. Following several washes with PBS, the secondary fluorescent antibody was added and incubated for $2 \mathrm{~h}$ in dark conditions. Mounting was performed with vectashield-mounting medium or DAPI containing mounting medium to stain the nuclei from Vector Laboratories. When indicated, MitoTrackerRed CMXRos was added at a concentration of $50 \mathrm{nM} 1 \mathrm{~h}$ prior to fixation. Cell imaging was performed using either a confocal microscope (model MRC1024; Bio-Rad Laboratories; Hercules, CA) with LaserSharp software (version 3.2) or a Leitz Diaplan (Wetzlar, Germany) fluorescence microscope. For imaging analysis at least 200 cells in 12 randomly chosen microscopic fields were counted per experiment. Experiments were performed in triplicate. 
Harvested skin equivalents were fixed in $4 \%$ paraformaldehyde, embedded in paraffin, and cut into $5 \mu \mathrm{m}$ sections. Standard immunohistochemistry of cleaved caspase-3 was performed as specified by the manufacturer (Cell Signaling Technology). Specimens were incubated with 1:50 of anti-caspase-3 overnight. Detection was performed with an HRP-coupled secondary antibody and DAB chromogen. Terminal deoxynucleotidyl transferase dUTP nicked end-labeling (TUNEL) assay was performed according to manufacturer's instructions (DeadEnd Fluorometric TUNEL System from Promega; Madison, WI). To obtain cryosections, the skin equivalents or skin organ cultures were fixed in 2\% paraformaldehyde for $30 \mathrm{~min}$ and left overnight in $20 \%$ sucrose in PBS. The following day they were embedded in cryogel (tissue freezing medium, Leica) and sliced. Sections were used for immunofluorescence using Bax NT antibody (1:200) and secondary Alexa Fluor 488 antibody (1:500). Mounting of the sections was done in DAPI containing mounting medium.

\section{RESULTS}

\section{UVB induces redistribution of Bax to mitochondria and effector caspase activation in skin equivalents}

To elucidate the apoptotic response initiated by UVB irradiation in human keratinocytes at the molecular level, we choose to initiate our biochemical analysis in skin equivalents, as this in vitro biological system reconstitutes histologically normal epidermis.

In situ labeling of apoptotic cells was evaluated by the TUNEL assay, indicating cells with fragmented DNA and by DAPI staining, showing the characteristic condensed morphology of the apoptotic nuclei. After exposure of the skin equivalents to $100 \mathrm{~mJ} / \mathrm{cm}^{2} \mathrm{UVB}$, sunburn/apoptotic cells were clearly distinguishable $10 \mathrm{~h}$ after UVB and became progressively more abundant after $24 \mathrm{~h}$ of UVB exposure (Fig. 1A).

Staining of the skin equivalent sections with an activation-specific anti-caspase-3 antibody revealed that activated caspase- 3 was present in sunburn/apoptotic cells and its level of activation increased with the time (Fig. 1B). In addition, Western blot analysis in lysates of UVB-treated skin equivalents evidenced that procaspase-3 cleavage was indeed taking place (Fig. 1C). Increased phosphorylation of p38 MAPK was also detected following exposure of the epidermal equivalents to UVB (Fig. 1C).

Because the pro-apoptotic Bax is a critical mediator of the mitochondrial pathway of caspase activation, we investigated whether redistribution of Bax was taking place under our experimental conditions. Immunofluorescence microscopy, using a conformation-specific Bax antibody that reacts with activated and membrane-targeted Bax, revealed that in apoptotic keratinocytes Bax was redistributed from a diffuse pattern to a predominantly perinuclear punctuated pattern, in contrast to the diffuse staining of Bax in the cytosol of the sham-irradiated skin equivalents (Fig. 1D).

To provide evidence for the mitochondrial localization of Bax in the UVB-irradiated cells and to position this signaling event in the apoptotic cascade leading to effector caspase activation, we performed an immunocytochemical analysis in the spontaneously immortalized human keratinocyte HaCaT cell line. 
Double immunostaining with cytochrome $c$ and Bax antibodies showed that, although in untreated cells cytochrome $c$ had only a punctuated mitochondrial distribution, in UVBirradiated cells where Bax was translocated, both a diffuse cytosolic staining of cytochrome $c$ and chromatin fragmentation were observed (Fig. 2).

Immunofluorescence analysis using the conformation-specific Bax antibody showed that the perinuclear fluorescent speckled pattern, which indicated redistributed Bax in the UVB-treated $\mathrm{HaCaT}$ cells, co-localized with the signal obtained by the mitochondrion-selective dye MitoTrackerRed, suggested a translocation of Bax from the cytosol to the mitochondria (Fig. $\underline{3 A})$. This process was detectable as early as $3 \mathrm{~h}$ after irradiation (data not shown), matching the onset of cytochrome $c$ release into the cytosol and clearly preceding maturation of procaspase- 3 (Fig. 3B).

Time course experiments measured by FACS analysis with the mitochondrial-sensitive dye $\mathrm{DiOC}_{6}$ (Fig. 3C) revealed that the loss in mitochondrial transmembrane potential, a major endpoint of the apoptotic process, occurred at 16-20 h after exposure of the cells to UVB. This apoptotic event was clearly downstream of the cytochrome $c$ release and took place in concomitance with the peak of caspase-3 activation.

Similar results were obtained in primary cultures of normal human keratinocytes (NHK), as well as in skin equivalents, which suggests that Bax translocation, cytochrome $c$ release and effector caspase activation, are major apoptotic signaling events occurring in normal epidermis in response to UVB irradiation.

\section{p38 $\alpha$ and p38 $\beta$ MAPK are major mediators of the intrinsic pathway of apoptosis in UVB- irradiated keratinocytes}

Figure $1 C$ shows that under the UVB irradiation conditions used to induce the formation of sunburn/apoptotic cells in skin equivalents, phosphorylated/activated p38 MAPK could be detected by Western blot. To provide more detailed and conclusive evidence for a role of p38 MAPK in UVB induced apoptosis, we produced a HaCaT cell line stably overexpressing a drug resistant $\mathrm{p} 38 \alpha$ (DRp38 $\alpha$ ) MAPK mutant. This $\mathrm{p} 38 \alpha$ MAPK mutant contains mutations in residues that are critical for pyridynil imidazole inhibitor binding (Thr106Met, His107Pro, and Leu108Phe), thereby making this p38 MAPK isoform insensitive to the chemical inhibitors PD169316 and SB203580 (29). However, the DRp38 $\alpha$ MAPK fully retains the ability to be activated by the same cellular stresses that promote the activation of the endogenous $\mathrm{p} 38 \alpha$ MAPK.

Exposure of the DRp38 $\alpha$ MAPK HaCaT cell line to UVB induced rapid activation of the endogenous p38 MAPKs as well as of the p38 $\alpha$ MAPK mutant. However, only the endogenous enzymes were negatively affected by the presence of SB203580 as shown by the reduced phosphorylation state of the endogenous p38 MAPK (Fig. 4B), and as also confirmed by immunocomplex kinase assay (see Fig. 6B).

Consistent with the enhanced level of UVB-induced p38 MAPK activation in these cells, irradiation of the DRp38 $\alpha$ MAPK expressing HaCaT cells with a UVB dose as low as $20 \mathrm{~mJ} / \mathrm{cm}^{2}$ 
significantly enhanced the release of cytochrome $c$ and overall cell death compared with the empty vector-expressing control cells ( $\underline{\text { Fig. } 4 A}, \underline{C})$.

The DRp38 $\alpha$ MAPK cells were less sensitive to the cytoprotective effects of the chemical inhibitors, as revealed by the analysis of cytochrome $c$ release, procaspase- 3 processing, and cleavage of its prototype substrate PARP in mock vs. DRp38 $\alpha$ MAPK overexpressing cells (Fig. $\underline{4 C})$. The observation that in DRp38 $\alpha$ MAPK transfectants the inhibition exerted by the SB203580 on cytochrome $c$ release and apoptosis was significantly, albeit not completely reversed, suggests that the endogenous and SB203580-sensitive p38 $\beta$ MAPK isoform contribute to these inhibitory effects as well.

As an alternative experimental approach we transduced $\mathrm{HaCaT}$ and $\mathrm{NHK}$ cells with an adenovirus that expresses a dominant negative p38 $\alpha$ MAPK (Ad-DNp38) mutant. Adenovirusmediated gene transfection of the keratinocytes accounted for $99 \%$ of the cell population as determined by FACS analysis of the co-expressed GFP (data not shown). The comparison between NHK and HaCaT cells may reveal whether the functional status of p53 is relevant for the p38 MAPK cytochrome $c$ releasing activity, since NHK contains wild-type (wt) p53, whereas $\mathrm{HaCaT}$ cells, carrying point mutations in both p53 alleles, express mutated p53 (30).

Inhibition of p38 MAPK prevented UVB-induced cell killing, as judged by the decreased level of PARP cleavage and by the reduced number of cells with the characteristic apoptotic morphology, compared with control cells infected with the empty vectors (Fig. 5B). This protective effect was somehow stronger and prolonged in the NHK than in HaCaT cells and probably reflects the higher (ig. $5 A$ ) and more persistent expression of the Ad-DNp38 MAPK mutant obtained in the former cells (data not shown). Correspondingly, expression of the AdDNp38 MAPK mutant in both NHK and HaCaT cells reduced the release of cytosolic cytochrome $c$ in response to UVB irradiation (Fig. 5C). The cytoprotective effect of the chemical p38 MAPK inhibitors was thus mimicked by the overexpression of the Ad-DNp38 MAPK, in both $\mathrm{HaCaT}$ and NHK cells, which suggests a general function of this signaling pathway in keratinocytes.

All together these data reinforce the role of p38 $\alpha$ MAPK as critical mediator of the mitochondrial pathway of apoptosis in UVB-irradiated human keratinocytes in cells expressing wt or mutated p53. Moreover, these results provide evidence for the specificity of the effects of the chemical inhibitors of $\mathrm{p} 38$ MAPK used.

\section{p38 MAPK is required for Bax translocation to the mitochondria following UVB}

Having provided clear evidence for the involvement of p38 MAPK in the UVB-induced apoptosis, we next asked how p38 MAPK mediates mitochondrial cytochrome $c$ release. Because UVB-induced p38 MAPK activation is positioned upstream to the release of cytochrome $c$ and because Bax is translocated to mitochondria in association with this event (igs. 2 and $\underline{3}$ ), we evaluated the possibility that p38 MAPK could mediate its apoptogenic effect by mobilizing Bax to the mitochondria.

To test this possibility, we pretreated HaCaT cells with the chemical inhibitors of p38 MAPK, prior to UVB irradiation, and analyzed the intracellular Bax distribution by immunofluorescence. 
Cells in which p38 MAPK was inhibited by SB203580 showed a marked decrease in mitochondrial Bax translocation after UVB irradiation (Fig. 6A). Similar effects were obtained with PD169316, and indeed both chemical inhibitors abolished p38 MAPK activation in response to UVB equally well (Fig. 6B) . Furthermore, the pharmacological inhibition of p38 MAPK reduced cytochrome $c$ release and protected the mitochondria from $\Delta \Psi_{\mathrm{m}}$ drop in response to UVB exposure (Fig. $6 B, \underline{C})$.

Conversely, in the UVB-irradiated DRp38 $\alpha$ MAPK cells this death signal was not only amplified, as judged by the increased percentage of cells showing intracellular Bax relocation, but was also insensitive to the inhibitory effects of SB203580 (Fig. 7).

To test the possibility of a direct association between activated p38 MAPK and Bax, we performed co-immunoprecipitation assays from untreated and UVB-irradiated lysates. Immunoprecipitation of either phospho-p38 MAPK or Flag-tagged p38 MAPK from HaCaT cells overexpressing DRp38 $\alpha$ MAPK, did not reveal any association with Bax, neither did the immunoprecipitation of Bax reveal associated phospho-p38 MAPK (data not shown).

The absence of a p38/Bax complex is suggestive for the participation of an intermediate molecule, which still needs to be identified, in this signaling cascade.

\section{Bcl-2 overexpression blocks mitochondrial Bax translocation and apoptosis downstream to p38 MAPK}

We have recently shown that Bcl-2 overexpression in HaCaT cells abolishes mitochondrial cytochrome $c$ release and caspase activation and efficiently protects keratinocytes from UVBbut not from FasL-induced cell killing (11).

To position the anti-apoptotic role of Bcl-2 in the p38 MAPK-mediated cascade leading to cytochrome $c$ release, we investigated at what stage Bcl-2 would reverse the UVB-activated p38 MAPK-Bax cascade. Upon overexpression of Bcl-2 in the HaCaT cells, this protein was prevalently found in the membrane fraction, while only a small amount could be detected in the cytosol (data not shown).

Intriguingly, as shown by immunocytochemistry analysis (Fig. 8A, $\underline{B}$ ), overexpression of Bcl-2 drastically abrogated the conformational change of Bax and its intracellular redistribution in response to UVB irradiation. The efficacy of Bcl-2 in repressing Bax translocation matched its inhibitory effects on cytochrome c release and apoptosis (Fig. 8D), suggesting a causative correlation between these events.

It should be mentioned that, as reported in a previous study (11), the inhibitory effects of Bcl-2 became less evident with increasing the UVB dose. This is not surprising since higher UVB doses activate signaling pathways that cannot be prevented by Bcl-2 and likely involve the death receptor-mediated caspase-8 activation (11).

The activation of p38 MAPK by UVB was unaffected in the Bcl-2 overexpressing cells (Fig. $\underline{8 C})$, thus ordering this event upstream of the inhibition exerted by $\mathrm{Bcl}-2$ on the mitochondrial translocation of Bax. 
The translocation of Bax to the mitochondria in UVB irradiated keratinocytes is caspaseindependent

To assess the involvement of caspases in the relocation of Bax to the mitochondria, we treated the cells with the pan-caspase inhibitor zVAD-fmk prior to UVB irradiation. As shown in Fig. $\underline{9 A}$, Bax translocation occurred equally well in cells pretreated with the pan-caspase inhibitor zVAD-fmk, although caspase activity and UVB-induced apoptosis were clearly blocked (data not shown; 4, 11). Furthermore, zVAD-fmk did not alter the UVB induced p38 MAPK activation, nor did it significantly inhibit the onset of cytochrome $c$ release, although it blocked the progression of this process with time (Fig. 9B). In addition, zVAD-fmk protected the UVBtreated cells from major loss in mitochondrial transmembrane potential (data not shown), which occurred at the time of maximal caspase activation 16-24 h post-irradiation (Fig. 3C).

These data are consistent with a caspase-independent engagement of the early onset of mitochondrial cytochrome $c$ release and suggest that activated caspases regulate a mitochondrial feedback loop, which is required for the progression of apoptosis (31).

Hence, our results position p38 MAPK-mediated Bax translocation and early cytochrome $c$ release upstream of zVAD-inhibitable caspase activation in UVB-induced apoptosis.

\section{Inhibition of the p38 MAPK cascade in normal epidermis reduces UVB-induced Bax relocation and apoptosis}

We next endeavored to recapitulate UVB-mediated cellular stress responses leading to keratinocyte death in normal human epidermis. In particular, a short-term human skin organ culture was used to substantiate our results on the role of the p38 MAPK signaling cascade as a major commitment step of the UVB-induced cell killing. As shown in Fig. 10, exposure of human skin to UVB irradiation $\left(300 \mathrm{~mJ} / \mathrm{cm}^{2}\right)$ induced a time-dependent accumulation of sunburn/apoptotic cells, as revealed by nuclear staining with DAPI. Sunburn keratinocytes with apoptotic nuclei were abundantly scattered in the basal and suprabasal layer (Fig. 10) and became clearly recognizable $16 \mathrm{~h}$ after irradiation. Immunofluorescence analysis with the antiactive Bax antibody revealed, as the case of the skin equivalents, that apoptotic keratinocytes stained positive for Bax, thereby indicating Bax conformational change/activation in the dying cells. Pretreatment of the whole skin organ culture with the p38 MAPK inhibitor PD169316 did reduce the number of apoptotic cells in skin and it did block Bax intracellular redistribution (Fig. $\underline{10)}$.

This result reinforces the physiological significance of our observations obtained in cultured keratinocytes and in skin equivalents. Moreover, it shows that inhibition of p38 MAPK can significantly protect human skin from UVB-induced killing by preventing Bax translocation to mitochondria, which represents an early commitment step in the initiation of apoptosis of the UVB-damaged keratinocytes.

\section{DISCUSSION}

In the present study, we show for the first time that exposure of human skin to UVB irradiation, leading to the formation of sunburn/apoptotic cells, is associated with a rapid intracellular redistribution of the pro-apoptotic Bax protein. We report that in UVB-irradiated keratinocytes 
translocated Bax co-localizes with mitochondria and is redistributed with kinetics closely paralleling those of the cytochrome $c$ release, suggesting a causal correlation. This event precedes the activation of procaspase- 3 and other endpoints of the apoptotic process, such as chromatin fragmentation and loss of the mitochondrial transmembrane potential. In skin equivalents procaspase-3 processing was readily detectable following UVB, in agreement with the result of a recent study in UVB-irradiated human skin samples (32).

Assuming that, as in many other paradigms of apoptosis, the translocation of Bax from the cytoplasm to the mitochondria is a prerequisite for caspase activation via the release of cytochrome $c$, the next pertinent question to be answered was which signal promotes this event in response to UVB.

The activation of p38 MAPK by cellular stresses (reviewed in, 33) has been coupled to signaling to apoptosis (34-37) but also to cell survival $(27,38,39)$. This finding suggests that the functional role of the p38 MAP kinase pathway in cell death or survival is determined strictly in a cell type-dependent and stimulus-specific fashion and may selectively involve the activation of distinct p38 MAPK isoforms (40). Because the available p38 MAPK chemical inhibitors, such as SB203580 and PD169316, specifically block the p38 $\alpha$ and p38 $\beta$ MAPK isoforms, these inhibitors have been largely used in studies that endeavor to understand the functional role of these enzymes in different cellular responses. It is known that the p38 $\alpha$ and p38 $\beta$ MAPK isoforms are expressed in human keratinocytes, and these have been implicated in both the regulation of normal keratinocyte differentiation and in the keratinocyte response to stress (41, 42). Previous studies have shown that pharmacological inhibition of the p38 MAPK signal in keratinocytes results in reduced caspase- 3 activation and protection from cell death in response to UVB (4, 23). Recently, mice treated with the p38 MAPK inhibitor SB202190 have been shown to be protected from acute UV-induced cellular responses including inflammation, epidermal hyperplasia, and sunburn cells formation (43), further implicating SB202190-sensitive p38 MAPKs in UVB-induced effects in vivo. Moreover, deficiency in the stress-inducible gene Gadd45a has been reported to cause resistance to UVB-induced apoptosis; compromise UVBmediated p38 MAPK, JNK, and p53 activation; and increase the incidence of solar-radiationinduced tumors, which suggests an additional link between p38 MAPK and the apoptotic machinery in murine epidermis (44).

In this study we provide conclusive evidence for the requirement of p38 MAPK for the onset of the mitochondrial pathway of apoptosis in UVB exposed human skin. First, we show that in UVB-irradiated HaCaT cells stably expressing a DRp38 $\alpha$ MAPK mutant, which fully retains the ability to be activated by UVB but is insensitive to the chemical p38 MAPK inhibitors, mitochondrial cytochrome $c$ release and apoptosis are augmented while the cytoprotective effects of SB203580 or PD169316 on these processes are considerably reversed. Second, we demonstrate that adenoviral-mediated transfection of a DN-p38 MAPK, significantly reduces cytochrome $c$ release and apoptosis, in both $\mathrm{HaCaT}$ and NHK cells. Because the $\mathrm{HaCaT}$ cells express mutated, transcriptionally inactive p53 (30), these results suggest that the transcriptional activity of p53 is dispensable for this p38 MAPK-mediated death signal. Moreover, the cytochrome $c$ releasing effect of activated p38 MAPK is not reduced by the broad-spectrum caspase inhibitor zVAD-fmk, demonstrating that p38 MAPK-induced activation of the mitochondrial cell death pathway is not a secondary consequence of caspase activation. 
Most importantly, we show that the UVB-mediated activation of p38 MAPK is required to induce the intracellular redistribution of Bax from the cytosol to the mitochondria. This finding is supported by different experimental evidences. The conformational change of Bax leading to its mitochondrial redistribution is not observed in UVB-irradiated keratinocytes in which p38 MAPK has been inhibited. Furthermore, p38 MAPK inhibition is associated with the inhibition of mitochondrial cytochrome $c$ release and effector caspase activation and with a protection from loss in mitochondrial transmembrane potential. All these effects are specifically reversed in the DRp38 $\alpha$ MAPK overexpressing cells. Moreover, inhibition of p38 MAPK in skin organ cultures leads to protection against UVB-induced cell death and concomitantly abolishes the redistribution of Bax in the basal layer of the epidermis where sunburn cells are also found. Together, these data establish that p38 MAPK plays a key physiological role in the activation of the mitochondrial cell death pathway in human keratinocytes in response to UVB irradiation.

To our knowledge this is the first report identifying Bax as a downstream target of the proapoptotic p38 MAPK cascade in UVB irradiated human skin. This finding is an important one as the way by which mitochondrial membrane integrity is controlled in UVB-exposed keratinocytes in vivo is of crucial relevance to devise pharmacological approaches promoting the rapid removal of potentially mutagenic UVB-damaged keratinocytes. Our results support observations recently made in other cellular systems involving the stress-activated protein kinases in the regulation of the mitochondrial pathway of apoptosis (45-48).

Although most studies in the literature describe a role for JNK in the regulation of pro-apoptotic Bcl-2 family members, some very recent studies have involved p38 MAPK as well $(28,37,49$, 50). In particular, in nitric oxide-treated neurons (49) and in mitotically arrested HeLa cells exposed to microtubule-interfering drugs (37), expression of constitutively active MKK3 (49) or MKK6 (37), the direct activators of p38 MAPK, was shown to promote Bax translocation from the cytosol to the mitochondria in a SB203580-inhibitable way. Furthermore, a reduced expression of Bax and a diminished sensitivity to stress-induced apoptosis has been shown in fibroblasts and cardiomyocytes derived from $\mathrm{p} 38 \alpha^{-/-}$MAPK mice, revealing a role for this protein kinase in the up-regulation of Bax (36). In our hands however, no major up-regulation of Bax in UVB-irradiated keratinocytes was observed, suggesting that the way by which p38 $\alpha$ MAPK regulates the mitochondrial pathway of apoptosis can be cell type as well as stressspecific.

The results presented here indicate that the p38 MAPK-Bax death cascade can be overruled by the overexpression of Bcl-2. Indeed, overexpression of Bcl-2 remarkably blocked the Bax conformational change required for its mitochondrial translocation, cytochrome $c$ release and apoptosis in response to UVB without interfering with p38 MAPK activation. In the Bcl-2 overexpressing cells this protein was found predominantly in the particulate fraction and almost absent in the cytosol, and it is still unclear which one of these Bcl-2 pools can block the redistribution of Bax at the UVB dose used in these experiments.

Although the mechanism by which anti-apoptotic Bcl-2 members prevents Bax activation is not completely deciphered, some studies propose that organelle-bound Bcl-2 would protect mitochondrial membranes by sequestering pro-apoptotic "BH3 only" proteins, thereby preventing them from activating Bax (51-53). Hence an interesting possibility would involve a "BH3 only" protein functioning downstream of p38 MAPK and upstream of Bax in the UVB- 
mediated apoptotic pathway. This intermediate protein could be sequestered away from the p38 MAPK-cascade, leading to Bax mitochondrial relocation, by the overexpression of Bcl-2.

The existence of a third partner could provide an explanation for the lack of direct interaction between p38 MAPK and Bax. Among the possible candidates, it is unlikely that truncated Bid (tBid) participates in our system, as the broad-spectrum caspase inhibitor zVAD-fmk, which would block caspases- and lysosomal proteases-mediated Bid cleavage in our experimental setup $(11,54)$, did not affect the intracellular Bax redistribution. This finding is consistent with the observation that the UVB-induced translocation of Bax and the onset of cytochrome $c$ release proceed initially independent of caspase activation in our system. Moreover, the UVB-induced Bid cleavage in HaCaT cells is blocked by overexpression of Bcl-2 (11), suggesting that within a certain range of UVB doses tBid may be generated through a mitochondria-mediated amplification loop involving active caspase-3, as also proposed in other studies $(10,55)$.

In conclusion, our data are consistent with a model of UVB-induced apoptosis in human skin in which activated p38 MAPK signals to Bax to engage the mitochondrial pathway of apoptosis. This death-signaling cascade is independent of active caspases and can be overruled by the overexpression of Bcl-2 (ig. 11). The present study identifies new elements in the signaling cascade that leads to mitochondrial membrane permeabilization in UVB-irradiated keratinocytes and suggests that p38 MAPK by committing keratinocytes to apoptosis could play a key role in preventing photocarcinogenesis.

\section{ACKNOWLEDGMENTS}

We thank U. Moens for the kind donation of the drug resistant and dominant negative p38 MAPK vectors and Z. Assefa for the FACS analysis. We also gratefully acknowledge Isabelle Cleynen and the technical assistance of H. Gillijns. This research was supported in part by Grant PV/12 from the Interuniversitaire Attractiepolen (IUAP) of the Federal Belgian Government, by

Grant 0211.99 from the Fonds voor Wetenschappelijk Onderzoek-Vlaanderen and by the Geconcerteerde Onderzoeksactie (GOA, from the KULeuven). Illustrations were supported by the "Universitaire Stichting" of Belgium. A. V. L. is a recipient of a PhD grant of the "Instituut voor de Aanmoediging van Innovatie door Wetenschap en Technologie in Vlaanderen."

\section{REFERENCES}

1. Kulms, D., Zeise, E., Pöppelmann, B., and Schwarz, T. (2002) Oncogene 21, 5844-5851

2. Murphy, G., Young, A. R., Wulf, H. C., Kulms, D., and Schwarz, T. (2001) Exp. Dermatol. 10, $155-160$

3. Smith, M., and Fornace, A. J. (1997) Proc. Natl. Acad. Sci. USA 94, 12255-12257

4. Assefa, Z., Vanthiegem, A., Garmyn, M., Declercq, W., Vandenabeele, P., Vandenheede, J. R., Bouillon, R., Merlevede, W., and Agostinis, P. (2000) J. Biol. Chem. 275, 21416-21421

5. Kraemer, K. H. (1997) Proc. Natl. Acad. Sci. USA 94, 11-14 
6. Decraene, D., Van Laethem, A., Agostinis, P., Degreef, H., Bouillon, R., and Garmyn, M. J. Invest. Dermatol., In press

7. Tron, V. A., Trotter, M. J., Tang, L., Krajewska, M., Reed, J. C., Ho, V. C., and Li, G. (1998) Am. J. Pathol. 153, 579-585

8. Acehan, D., Jiang, X., Morgan, D. G., Heuser, J. E., Wang, X., and Akey, C. W. (2002) Mol. Cell 9, 423-432

9. Wang, X. (2001) Genes Dev. 15, 2922-2933

10. Sitailo, L. A., Tibudan, S. S., and Denning, M. F. (2002) J. Biol. Chem. 277, 19346-19352

11. Assefa, Z., Garmyn, M., Vanthiegem, A., Declercq, W., Vandenabeele, P., Vandenheede, J. R., and Agostinis, P. (2003) FEBS Lett. 540, 125-132

12. Rodriguez-Villanueva, J., Greenhalgh, D., Wang, X. J., Bundman, D., Cho, S., Delehedde, M., Roop, D., and McDonnell, T. J. (1998) Oncogene 16, 853-863

13. Delehedde, M., Cho, S. H., Hamm, R., Brisbay, S., Ananthaswamy, H. N., Kripke, M., and McDonnell, T. J. (2001) J. Invest. Dermatol. 116, 366-373

14. Umeda, J., Sano, S., Kogawa, K., Motoyama, N., Yoshikawa, K., Itami, S., Kondoh, G., Watanabe, T., and Takeda, J. (2003) FASEB J. 17, 610-620

15. Muller-Rover, S., Rossiter, H., Paus, R., Handjiski, B., Peters, E. M., Murphy, J. E., Mecklenburg, L., and Kupper, T. S. (2000) Am. J. Pathol. 156, 1395-1405

16. Jost, M., Gasparro, F. P., Jensen, P. J., and Rodeck, U. (2001) J. Invest. Dermatol. 116, 860866

17. Grossman, D., Kim, P. J., Blanc-Brude, O. P., Brash, D. E., Tognin, S., Marchisio, P. C., and Altieri, D. C. (2001) J. Clin. Invest. 108, 991-999

18. van Loo, G., Saelens, X., van Gurp, M., MacFarlane, M., Martin, S. J., and Vandenabeele, P. (2002) Cell Death Differ. 9, 1031-1042

19. Danial, N. N., and Korsmeyer, S. J. (2004) Cell 116, 205-219

20. Assefa, Z., Garmyn, M., Bouillon, R., Merlevede, W., Vandenheede, J. R., and Agostinis, P. (1997) J. Invest. Dermatol. 108, 886-891

21. Pfundt, R., van Vlijmen-Willems, I., Bergers, M., Wingens, M., Cloin, W., and Schalwijk, J. (2001) J. Pathol. 193, 248-255

22. Eckert, R. L., Efimova, T., Dashti, S. R., Balasubramanian, S., Deucher, A., Crish, J. F., Sturniolo, M., and Bone, F. (2002) J Invest Dermatol Symposium Proceedings 7, 36-40 
23. Shimizu, H., Banno, Y., Sumi, N., Naganawa, T., Kitajima, Y., and Nozawa, Y. (1999) J. Invest. Dermatol. 112, 769-774

24. Gilchrest, B. A. (1983) J. Invest. Dermatol. 81, 148-189

25. Lippens, S., Kockx, M., Knaapen, M., Mortier, L., Polakowska, R., Verheyen, A., Garmyn, M., Zwijsen, A., Formstecher, P., Huylebroeck, D., et al. (2000) Cell Death Differ. 7, 12181224

26. He, T. C., Zhou, S., da Costa, L. T., Yu, J., Kinzler, K. W., and Vogelstein, B. (1998) Proc. Natl. Acad. Sci. USA 95, 2509-2514

27. Hendrickx, N., Volanti, C., Moens, U., Seternes, O. M., de Witte, P., Vandenheede, J. R., Piette, J., and Agostinis, P. (2003) J. Biol. Chem. 278, 52231-52239

28. Desbiens, K. M., Deschesnes, R. G., Labrie, M. M., Desfossés, Y., Lambert, H., Landry, J., and Bellmann, K. (2003) Biochem. J. 372, 631-641

29. Eyers, P. A., van den Ijssel, P., Quinlan, R. A., Goedert, M., and Cohen, P. (1999) FEBS Lett. 451, 191-196

30. Paramio, J. M., Segrelles, C., Lain, S., Gomez-Casero, E., Lane, D. P., Lane, E. B., and Jorcano, J. L. (2000) Mol. Carcinog. 29, 251-262

31. Ricci, J. E., Gottlieb, R. A., and Green, D. R. (2003) J. Cell Biol. 160, 65-75

32. Nickoloff, B. J., Qin, J. Z., Chatuverdi, V., Bacon, P., Panella, J., and Denning, M. F. (2002) J Invest Dermatol Symposium Proceedings 7, 27-35

33. Kyriakis, J. M., and Avruch, J. (2001) Physiol. Rev. 81, 807-869

34. Li, S.P., Junttila, M., R., Han, J., Kahari, V.M., and Westermarck, J. (2003) Cancer Res 63, 3473-3477

35. Schrantz, N., Bourgeade, M. F., Mouhamad, S., Leca, G., Sharma, S., and Vazquez, A. (2001) Mol. Biol. Cell 12, 3139-3151

36. Porras, A., Zuluaga, S., Black, E., Valladares, A., Alvarez, A. M., Ambrosino, C., Benito, M., and Nebreda, A. R. (2004) Mol. Biol. Cell 15, 922-933

37. Deacon, K., Mistry, P., Chernoff, J., Blank, J. L., and Patel, R. (2003) Mol. Biol. Cell 14, 2071-2087

38. Okamoto, S., Krainc, D., Sherman, K., and Lipton, S. A. (2000) Proc. Natl. Acad. Sci. USA 97, 7561-7566

39. Alvarado-Kristensson, M., Melander, F., Leandersson, K., Ronnstrand, L., Wernstedt, C., and Andersson, T. (2004) J. Exp. Med. 199, 449-458 
40. Pramanik, R., Qi, X., Borowicz, S., Choubey, D., Schultz, R. M., Han, J., and Chen, G. (2003) J. Biol. Chem. 278, 4831-4839

41. Eckert, R. L., Efimova, T., Blasubramanian, S., Crish, J. F., Bone, F., and Dashti, S. (2003) J. Invest. Dermatol. 120, 823-828

42. Bode, A. M., and Dong, Z. (2003) Sci. STKE 167, RE2

43. Hildesheim, J., Awwad, R. T., and Fornace, A. J. (2004) J. Invest. Dermatol. 122, 497-502

44. Hildesheim, J., Bulavin, D. V., Anver, M. R., Alvord, W. G., Hollander, M. C., Vardanian, L., and Fornace, A. J., Jr. (2002) Cancer Res. 62, 7305-7315

45. Yuan, Z. Q., Feldman, R. I., Sussman, G. E., Coppola, D., Nicosia, S. V., and Cheng, J. Q. (2003) J. Biol. Chem. 278, 23432-23440

46. Tsuruta, F., Sunayama, J., Mori, Y., Hattori, S., Shimizu, S., Tsujimoto, Y., Yoshioka, K., Masuyama, N., and Gotoh, Y. (2004) EMBO J. 23, 1889-1899

47. Putcha, G. V., Le, S., Frank, S., Besirli, C. G., Clark, K., Chu, B., Alix, S., Youle, R. J., LaMarche, A., Maroney, A. C., et al. (2003) Neuron 38, 899-914

48. Lei, K., and Davis, R. J. (2003) Proc. Natl. Acad. Sci. USA 100, 2432-2437

49. Ghatan, S., Larner, S., Kinoshita, Y., Hetman, M., Patel, L., Xia, Z., Youle, R. J., and Morrison, R. S. (2000) J. Cell Biol. 150, 335-347

50. Shou, Y., Li, L., Prabhakaran, K., Borowitz, J. L., and Isom, G. E. (2003) Toxicol. Sci. 75, 99-107

51. Antonsson, B., Montessuit, S., Sanchez, B., and Martinou, J. C. (2001) J. Biol. Chem. 276, 11615-11623

52. Cheng, E. H., Wei, M. C., Weiler, S., Flavell, R. A., Mak, T. W., Lindsten, T., and Korsmeyer, S. J. (2001) Mol. Cell 8, 705-711

53. Thomenius, M. J., Wang, N. S., Reineks, E. Z., Wang, Z., and Distelhorst, C. W. (2003) J. Biol. Chem. 278, 6243-6250

54. Rozman-Pungercar, J., Kopitar-Jerala, N., Bogyo, M., Turk, D., Vasiljeva, O., Stefe, I., Vandenabeele, P., Bromme, D., Puizdar, V., Fonovic, M., et al. (2003) Cell Death Differ. 10, $881-888$

55. Slee, E. A., Keogh, S. A., and Martin, S. J. (2000) Cell Death Differ. 7, 556-565

Received May 17, 2004; accepted August 16, 2004. 
Fig. 1

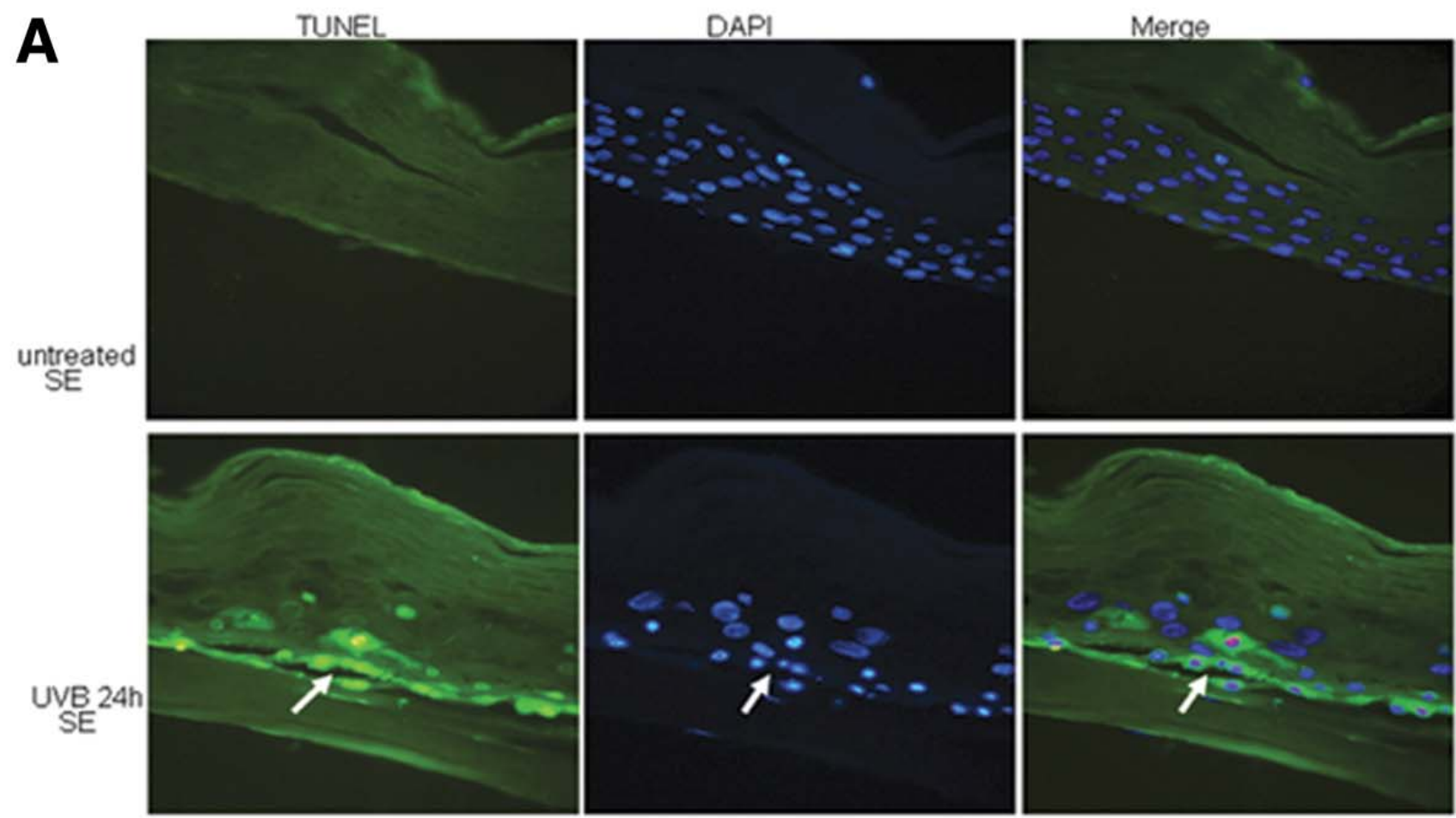

B

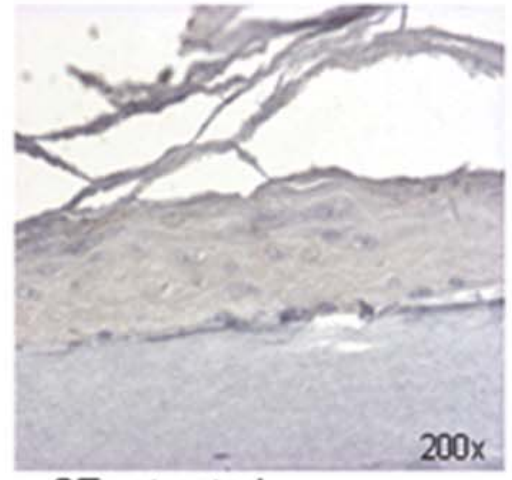

SE untreated

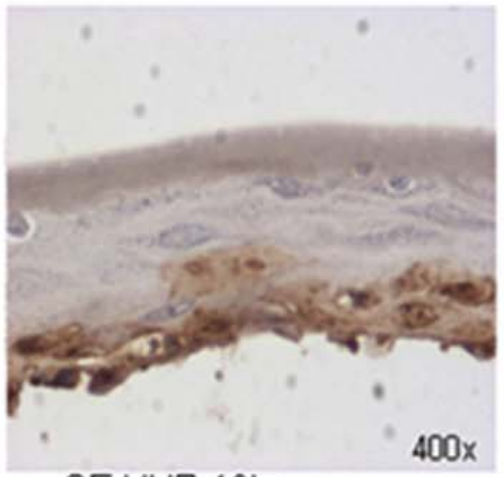

SE UVB 10h

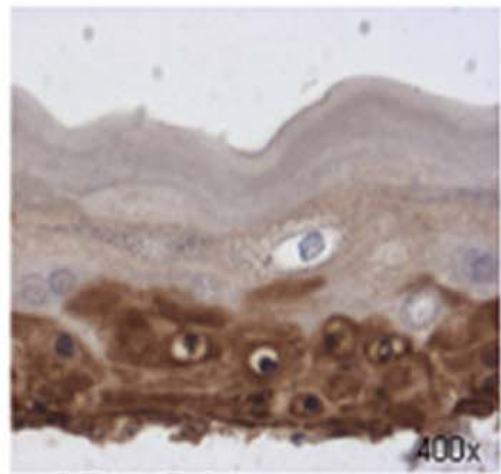

SE UVB 24h

C

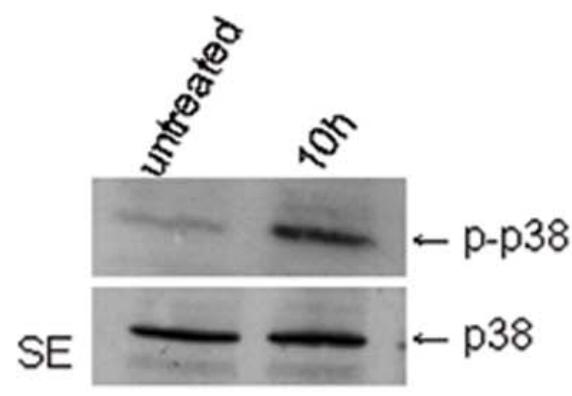

$\leftarrow 32 \mathrm{kDa}$ caspase-3

SE

$\leftarrow$ p19/p17kDa cleavage product 
Fig. 1 (cont)

D

untreated

SE

UVB $10 \mathrm{~h}$

SE
BaxNT
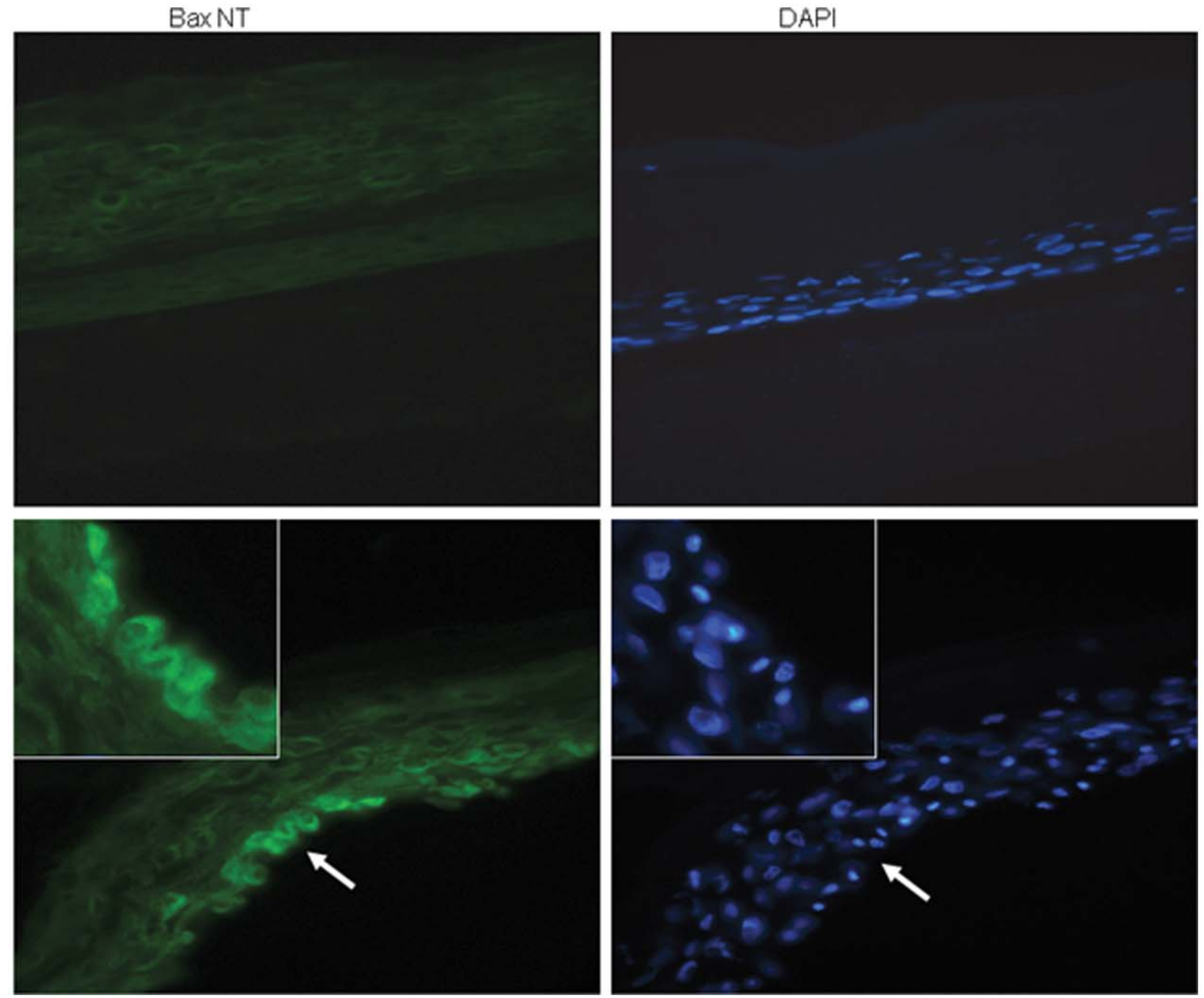

Figure 1. UVB-induced apoptosis of human skin is mediated via Bax translocation and effector caspase activation. A) TUNEL assay of untreated versus irradiated $\left(100 \mathrm{~mJ} / \mathrm{cm}^{2} \mathrm{UVB}\right.$ ) skin equivalents (SE) $24 \mathrm{~h}$ after irradiation, showing DNA fragmentation in cells of the basal and suprabasal layers (second row, left panel). DAPI-positive apoptotic nuclei of the same UVB irradiated SE are visible (middle panel and overlay). Arrows indicate TUNEL-positive cells or condensed nuclei (DAPI). B) Immunolocalization of the active caspase-3 cleavage product in the basal and suprabasal layers at 10 and $24 \mathrm{~h}$ after UVB $\left(100 \mathrm{~mJ} / \mathrm{cm}^{2}\right)$. $\boldsymbol{C}$ ) Western blot analysis of p38 MAPK phosphorylation and expression. $\boldsymbol{D}$ ) Immunostaining of Bax in irradiated skin equivalents at $10 \mathrm{~h}$ after UVB by using a conformation specific anti-active Bax antibody. Translocated Bax is revealed as punctuated pattern (green, left, arrow) in cells with condensed pyknotic nuclei (DAPI, arrow). Insets: magnification of the area indicated with arrows. 
Fig. 2

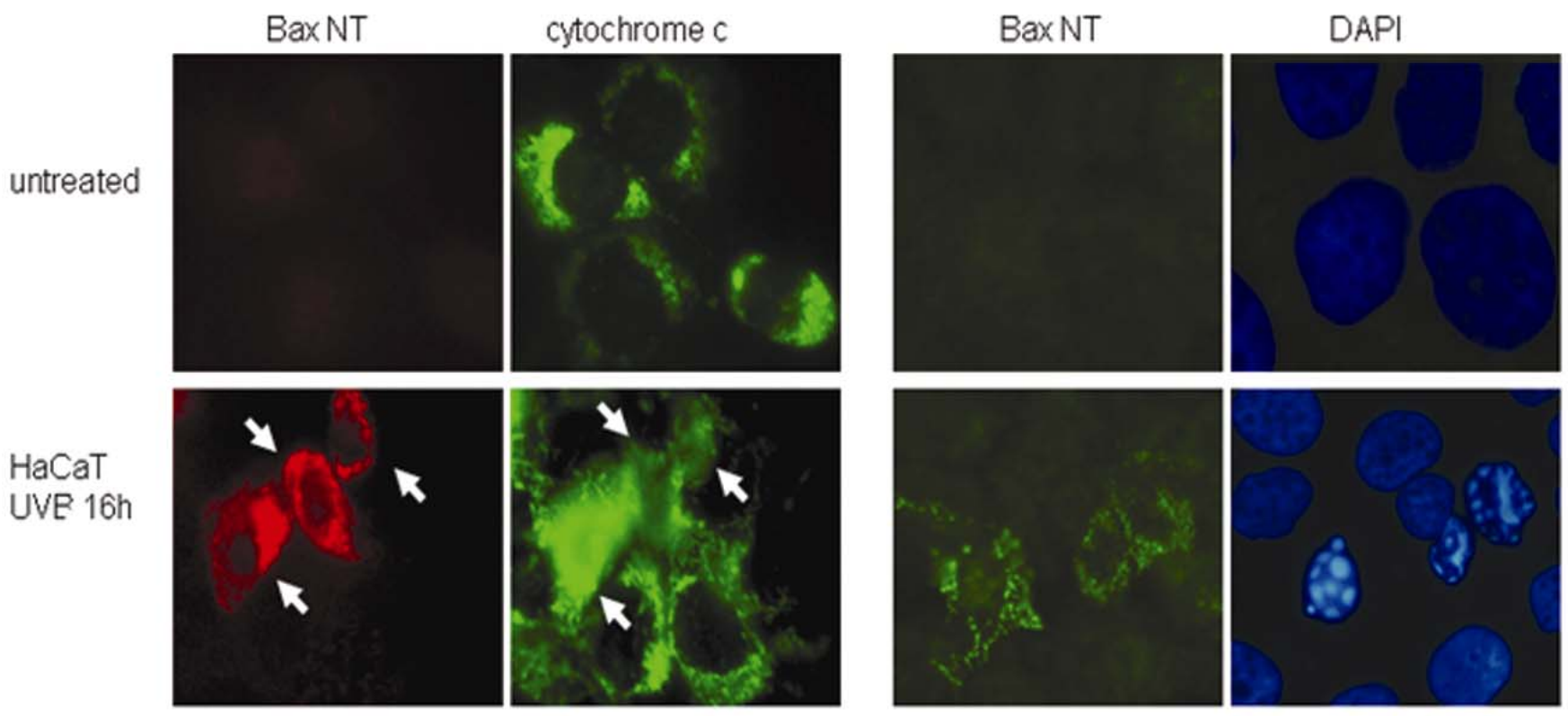

Figure 2. Bax translocation coincides with the cytosolic redistribution of cytochrome $c$ in UVB-induced apoptosis. Immunocytochemistry of UVB $\left(60 \mathrm{~mJ} / \mathrm{cm}^{2}\right)$ treated $\mathrm{HaCaT}$ cells $16 \mathrm{~h}$ after irradiation shows the translocated Bax (red, second row, first panel) that coincides with the cytosolic redistribution of cytochrome $c$ (green, second row, second panel). Arrows indicate Bax translocation (red) or cytosolic cytochrome $c$ distribution (green). Bax translocation (green, third panel, second row) and chromatin condensation shown by DAPI staining (blue, second row, right panel). 
Fig. 3

A
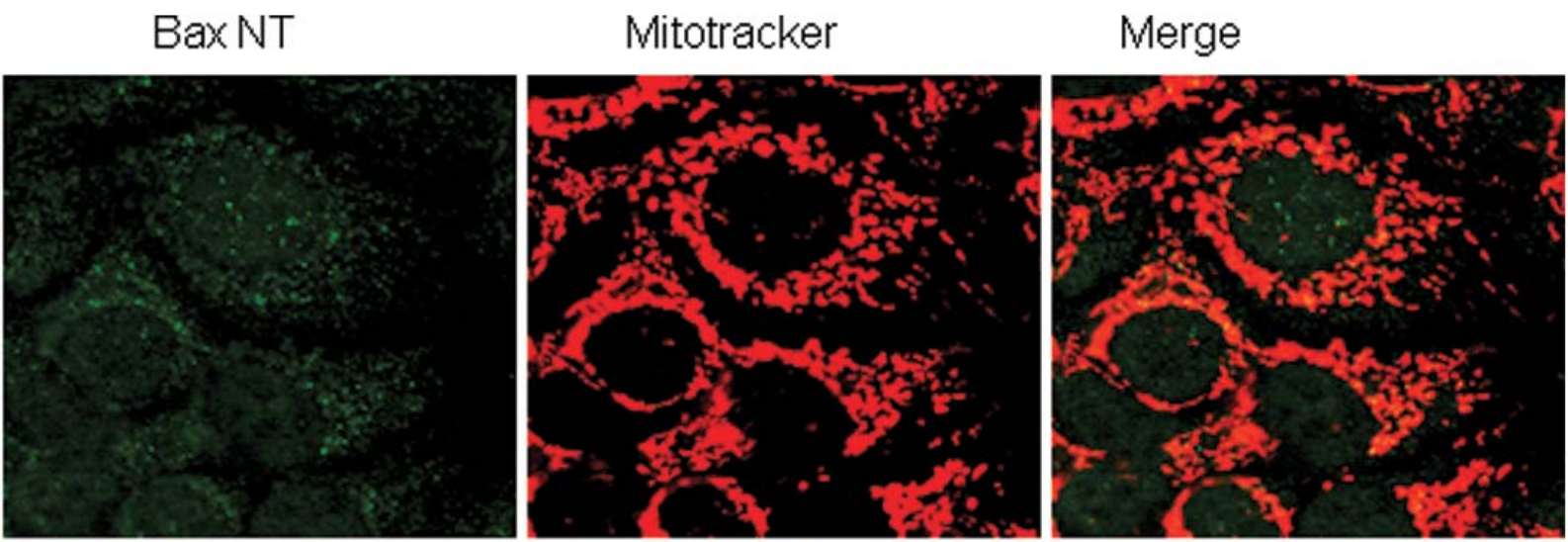

UVB
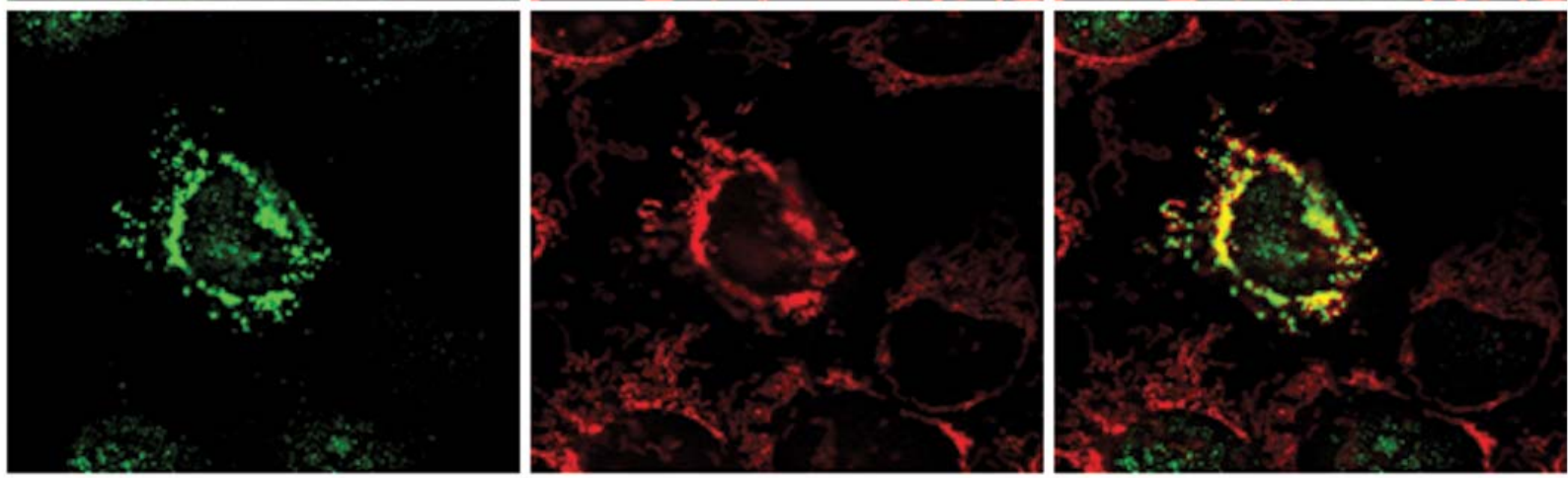

B

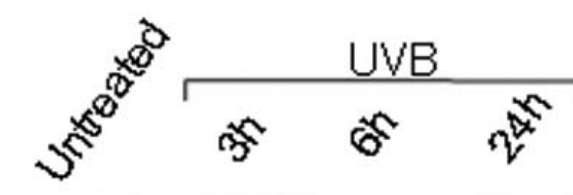

$\leftarrow$ cytochrome c

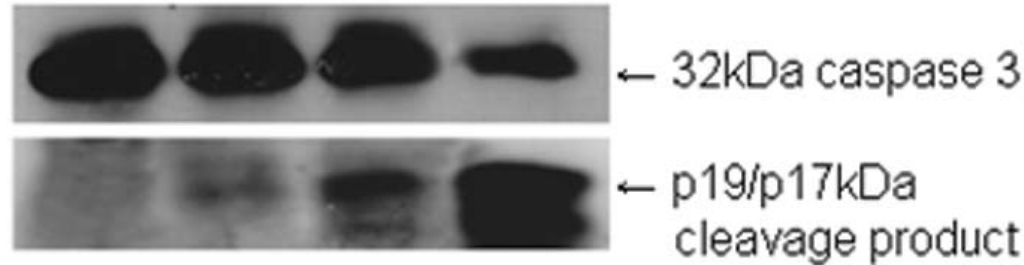


Fig. 3 (cont)
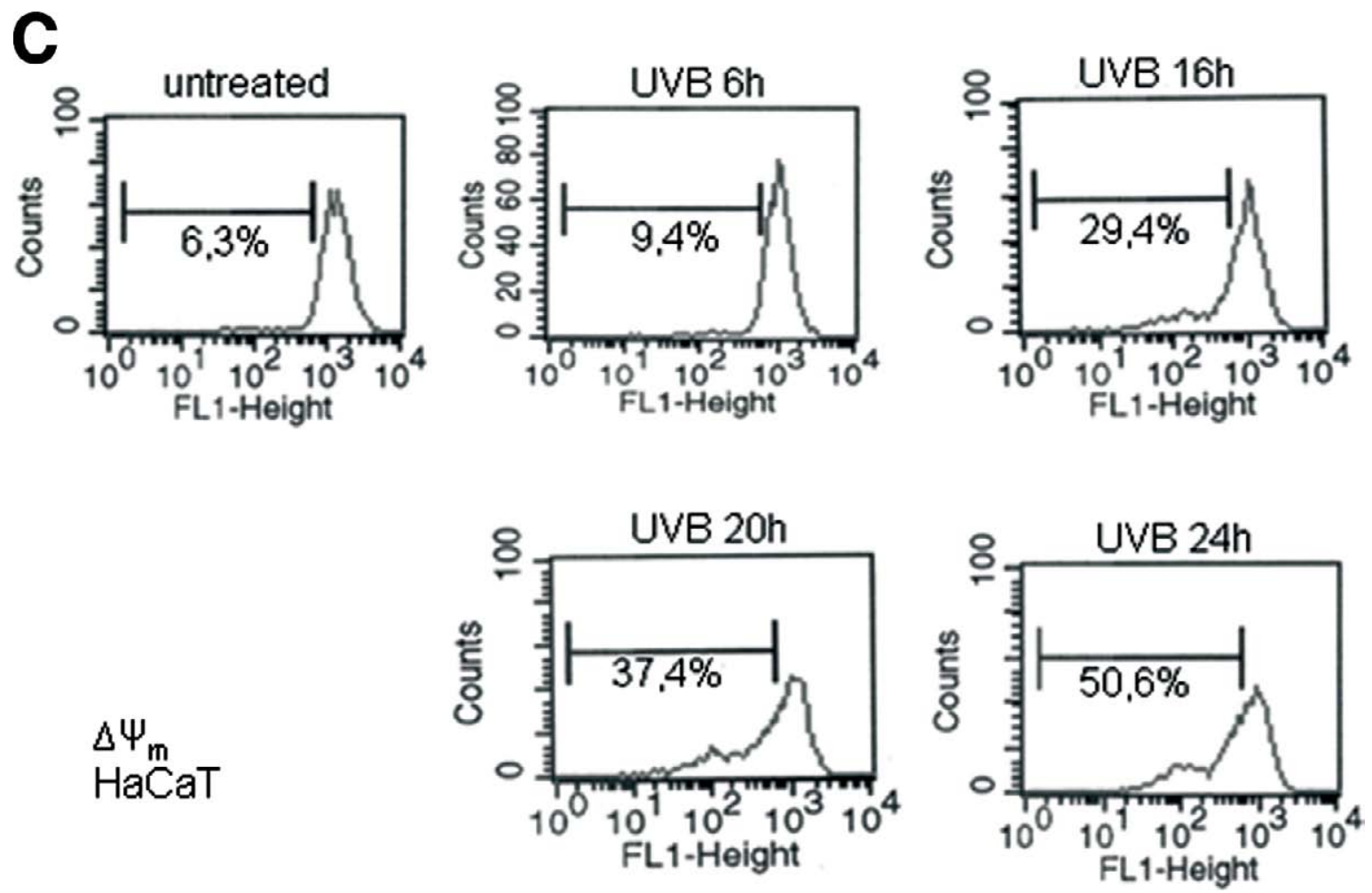

Figure 3. UVB induces mitochondrial localization of Bax during apoptosis in human keratinocytes. $A$ ) Immunocytochemistry of untreated HaCaT cells shows diffuse staining of Bax in the cytosol (upper panels, left) and Mitotracker-staining of the mitochondria (upper panels, middle and merge). UVB-irradiated cells $\left(60 \mathrm{~mJ} / \mathrm{cm}^{2}, 10 \mathrm{~h} \mathrm{post-}\right.$ irradiation) show the perinuclear speckled pattern of Bax (lower panels, left). Mitotracker overlay confirms the mitochondrial co-localization of Bax in these cells (lower panels, middle and merge). B) Time course analysis of mitochondrial cytochrome $c$ release and cleavage of procaspase-3 by Western blot. Cells were harvested at the indicated time points using Streptolysin O for permeabilization as described under Materials and Methods. Equal loading of proteins was verified using Ponceau S. C) Measurement of mitochondrial transmembrane potential loss after UVB treatment of $\mathrm{HaCaT}$ cells. At the indicated time points cells were trypsinized and incubated with the mitochondrial dye $\mathrm{DiOC}_{6}$ as described under Materials and Methods. Results from a representative experiment are shown. 
Fig. 4

A

UVB $16 \mathrm{~h}$ HaCaT-EV
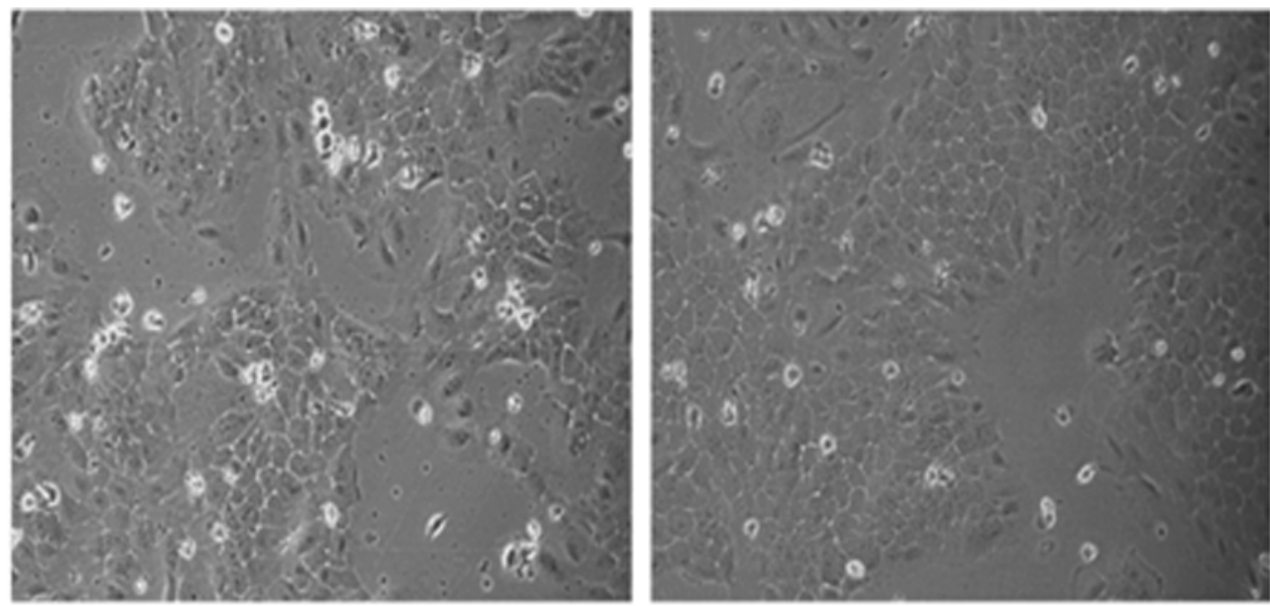

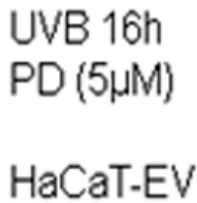

UVB $16 \mathrm{~h}$ HaCaT-DRp38
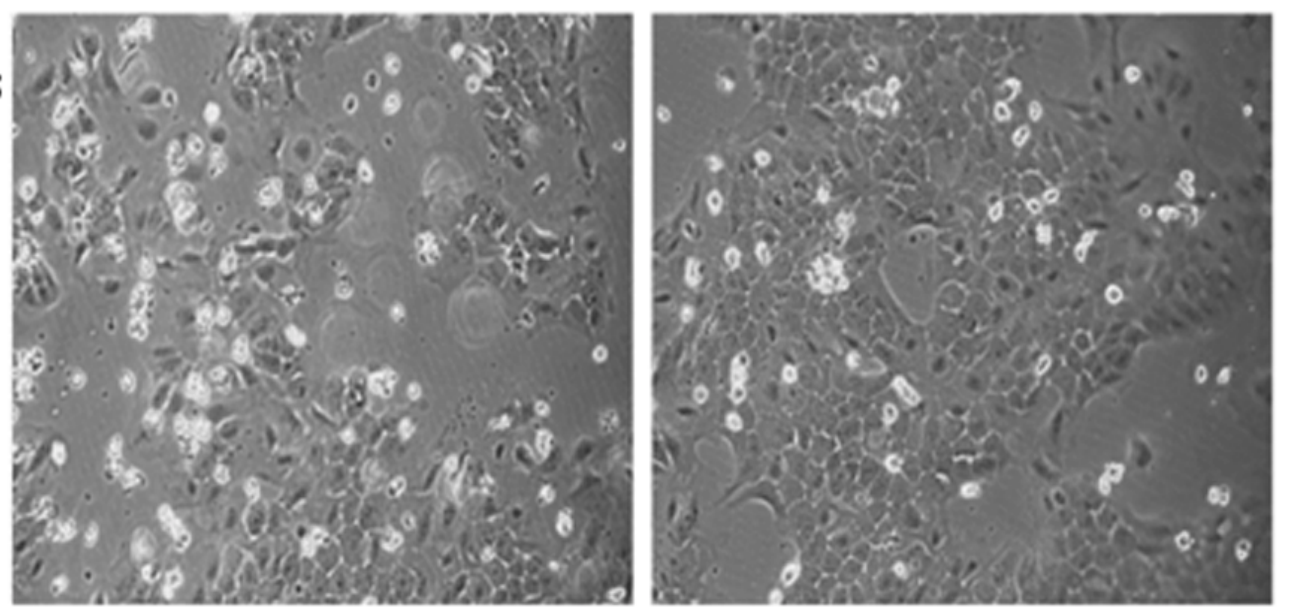

UVB 16h

$\mathrm{PD}(5 \mu \mathrm{M})$

HaCaT-DRp38

B
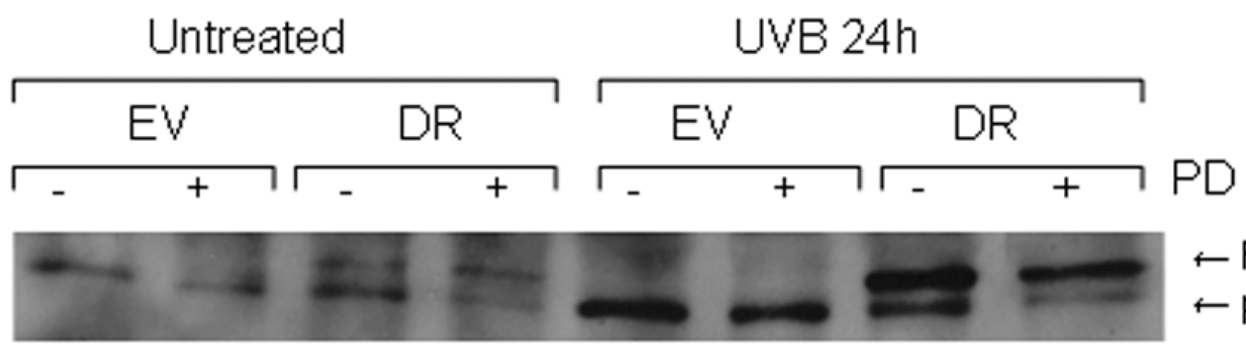

$\leftarrow$ Flag-tagged p-p38

$\leftarrow p-p 38$

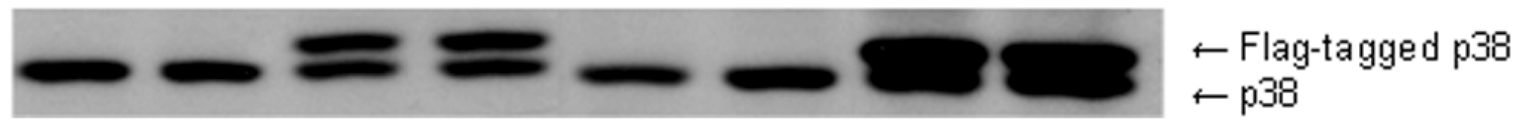


Fig. 4 (cont)
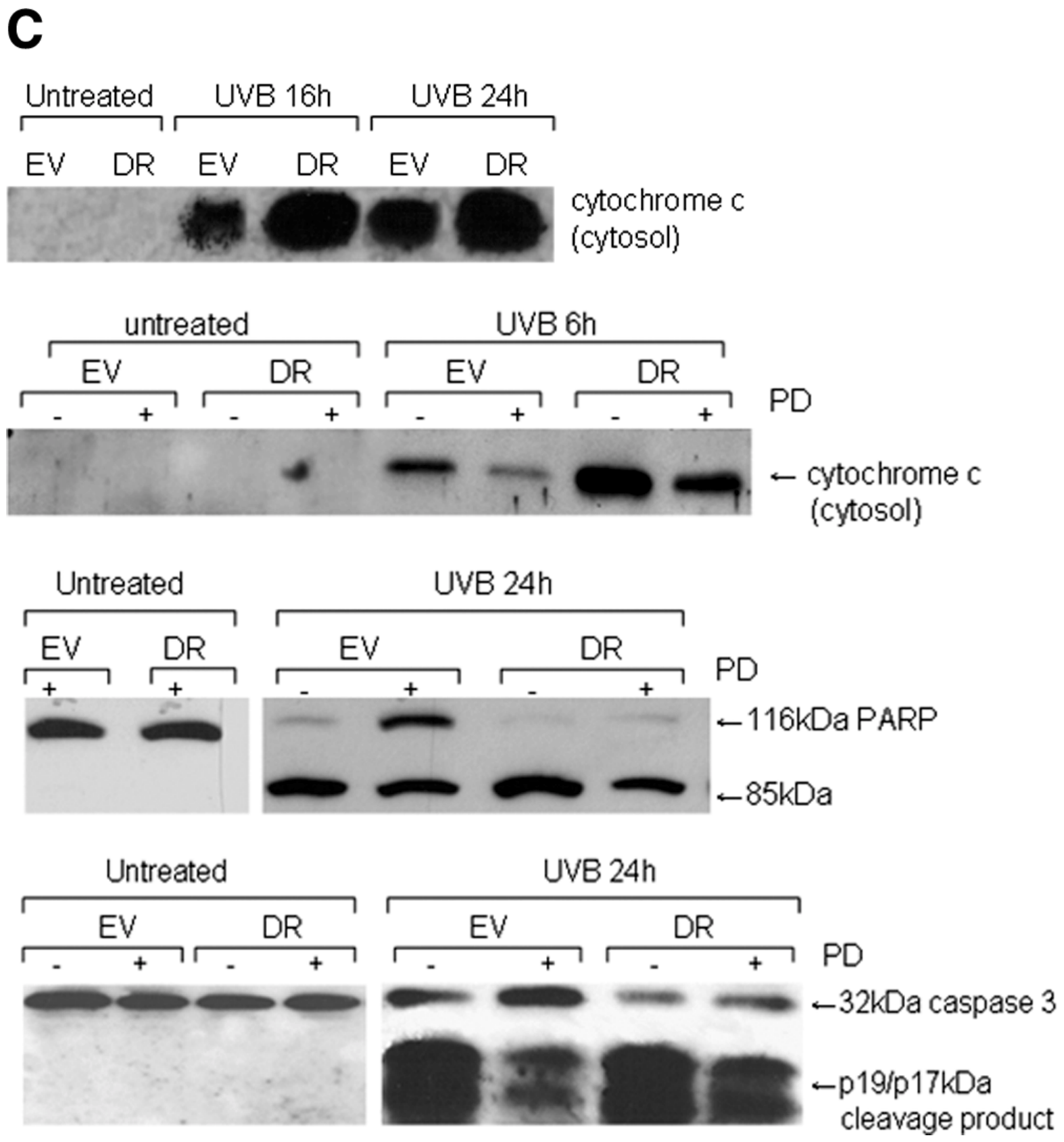

Figure 4. Overexpression of drug-resistant p38 $\alpha$ MAPK (DRp38 $\alpha$ ) mutant enhances the kinetics of UVB-induced apoptosis and reverts the protective effect of PD169316. $A$ ) Phase contrast microscopic analysis of UVB-treated HaCaT cells stably overexpressing empty vector (HaCaT-EV), upper panels, versus DRp38 $\alpha$ MAPK, lower panels. Pictures of irradiated non-treated cells (left) versus cells pre-treated with PD169316 (5 $\mu \mathrm{M}$; right) were taken $16 \mathrm{~h}$ after UVB (20 $\mathrm{mJ} / \mathrm{cm}^{2}$ ). B ) p38 $\alpha$ MAPK expression and activation in HaCaT-EV cells and in HaCaT-DRp38 $\alpha$ MAPK by Western blot. C) Western blot analysis of the enhanced apoptotic kinetics in the DRp38 $\alpha$ MAPK overexpressing cells compared with EV transfected cells. Comparison of cytochrome $c$, caspase-3 cleavage and PARP cleavage in HaCaT-EV and HaCaT-DRp38 $\alpha$ MAPK cells in non-treated versus cells pre-treated with $5 \mu \mathrm{M}$ of PD169316. 
Fig. 5

A

EV DN

B

UVB $16 \mathrm{~h}$
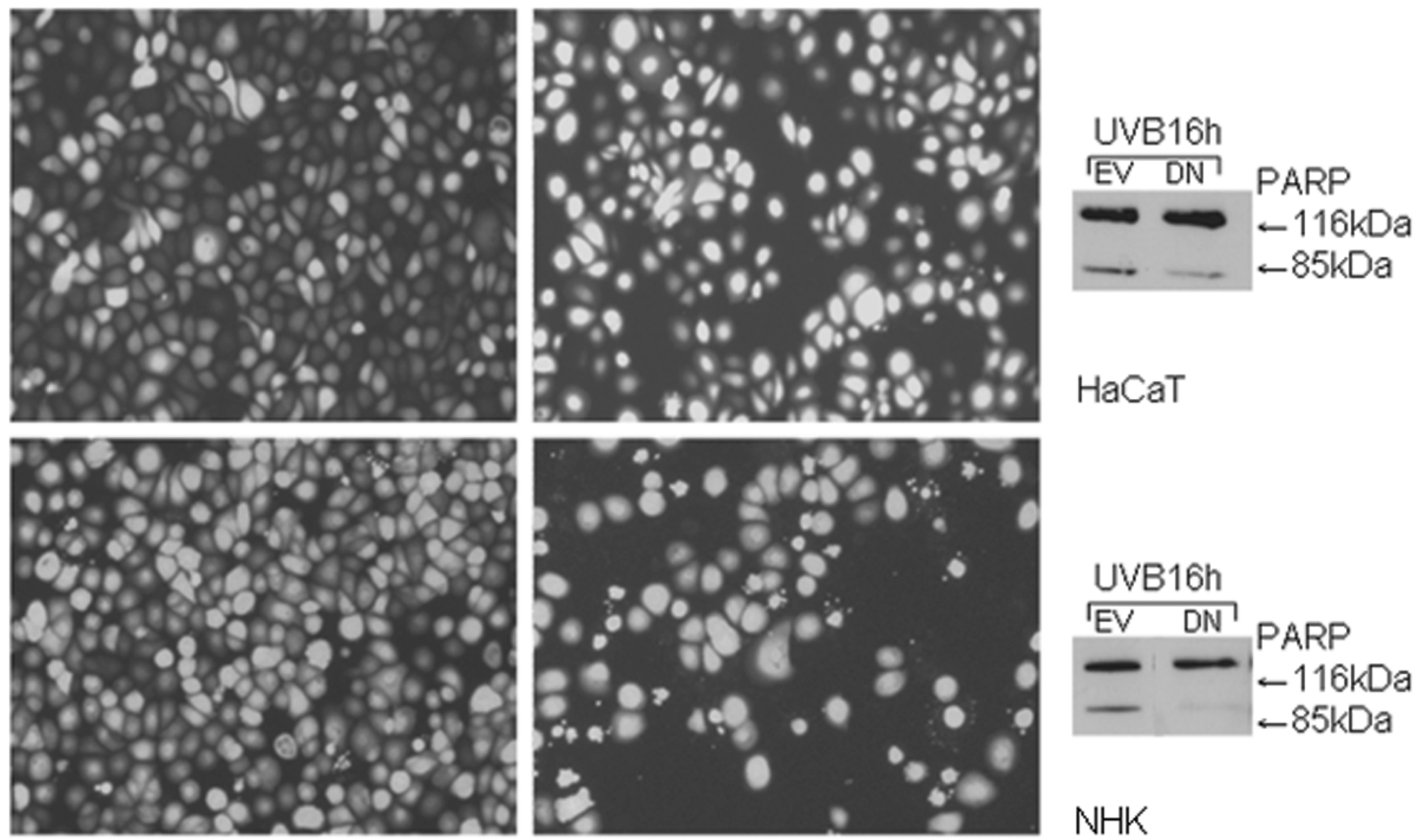

$\mathrm{HaCaT}$

Ad-DN p38

Ad-EV

C

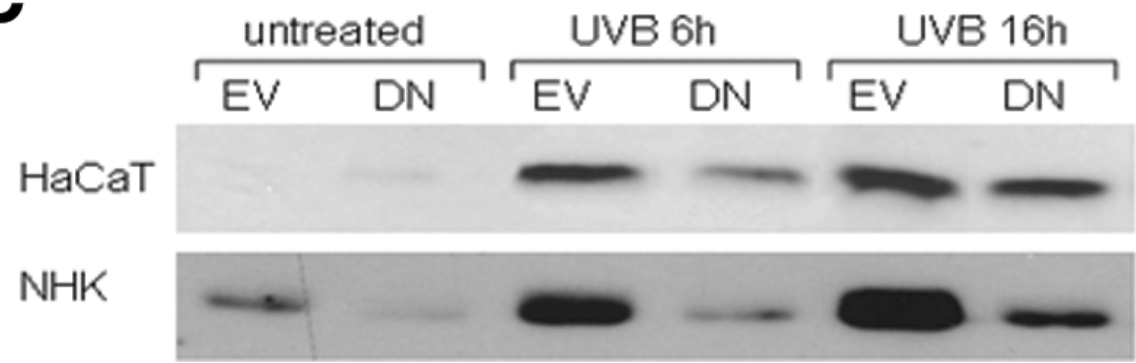

cytochrome c (cytosol)

Figure 5. HaCaT cells transfected with adenoviral dominant negative p38 MAPK (Ad-DNp38) are protected from UVB-induced apoptosis. A) Expression of Ad-DNp38 (Flag-tagged) in HaCaT cells and human primary keratinocytes. B) Morphologic analysis of transfected (Ad-DNp38 MAPK versus EV) cells. Pictures were taken at $16 \mathrm{~h}$ after UVB irradiation $\left(60 \mathrm{~mJ} / \mathrm{cm}^{2}\right)$, and the cells were subsequently lysed in HEPES containing buffer and analyzed for PARP cleavage by Western blot. $C$ ) Cytosolic cytochrome $c$ redistribution in Ad-DNp38 MAPK transfected HaCaT cells and human primary keratinocytes versus empty vector (EV) transfected cells. Cells were harvested at indicated time points after UVB irradiation and were permeabilized with Streptolysin O to obtain the cytosolic fraction. 
Fig. 6

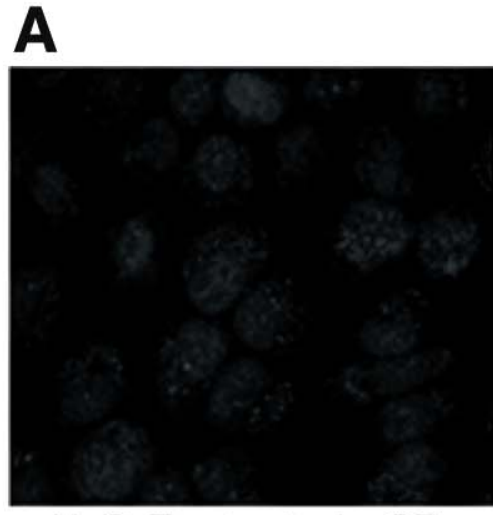

HaCaT untreated + SB

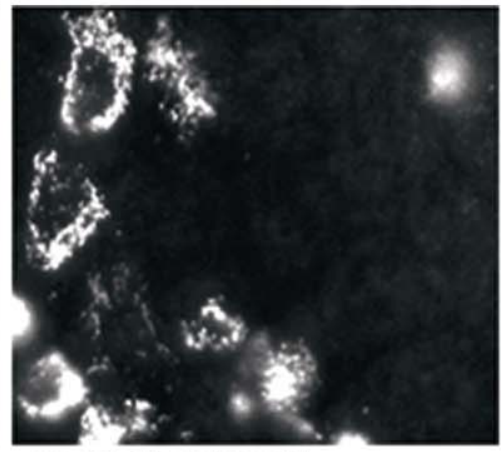

HaCaT UVB 10h

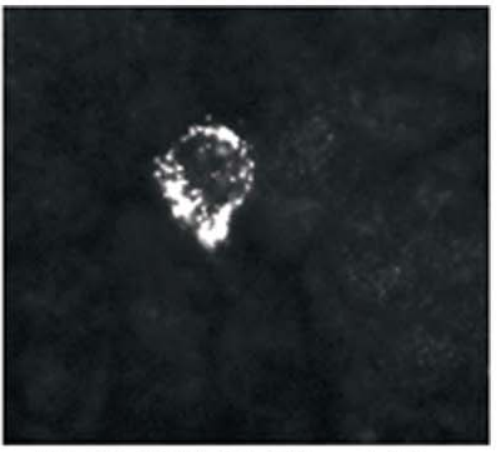

HaCaT UVB 10h + SB

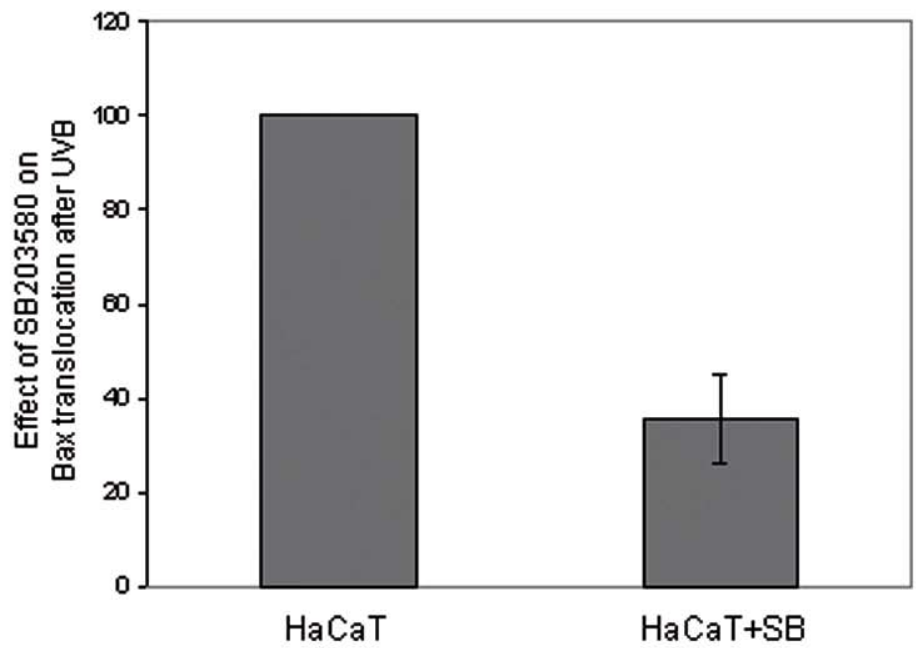

B
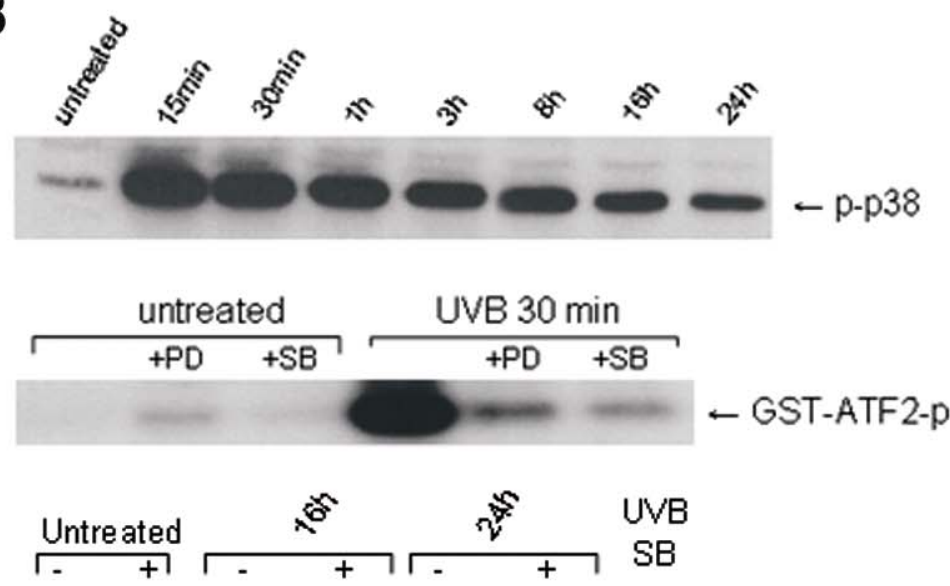

$\leftarrow$ cytochrome c (cytosolic) 
Fig. 6 (cont)

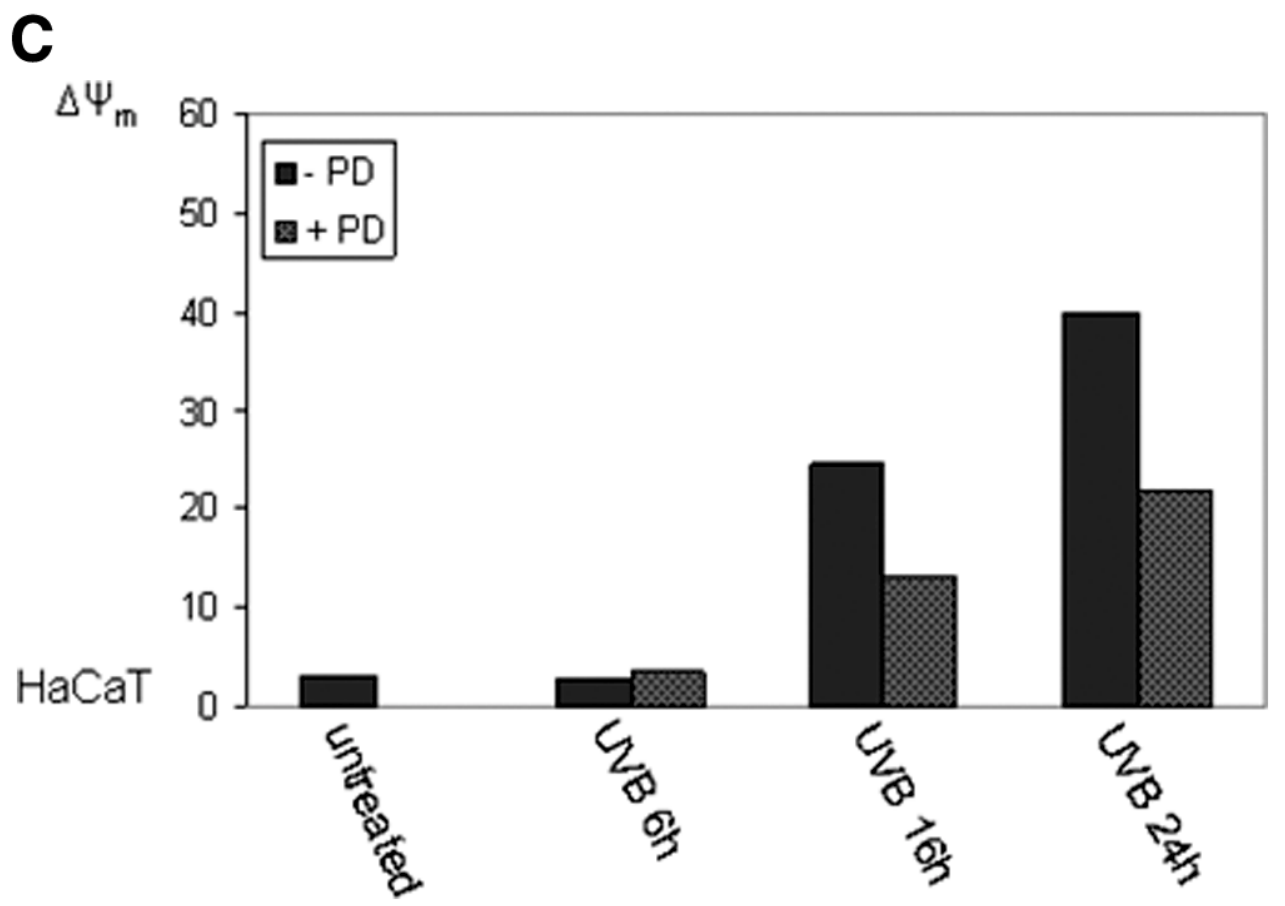

Figure 6. p38 MAPK mediates mitochondrial Bax translocation during UVB-induced apoptosis. HaCaT cells were pre-treated with SB203580 $(5 \mu \mathrm{M}) 1 \mathrm{~h}$ prior to UVB irradiation $\left(60 \mathrm{~mJ} / \mathrm{cm}^{2}\right)$ or $1 \mathrm{~h}$ prior to fixation in the untreated control. Ten hours after UVB the cells were fixed and processed for immunocytochemistry with anti-active Bax antibody. A) A representative field of each condition is shown. Not-irradiated controls without SB203580 were identical to the SBtreated controls shown in the picture. Lower panel shows a graph of the inhibitory effect of SB203580 treatment on Bax translocation relative to SB-untreated cells in which the percentage of cells showing translocated Bax after UVB irradiation is taken as $100 \%$. Error bars represent SD of at least 3 independent experiments in which at least 150 cells were counted in more than 10 fields. B) Time course of p38 MAPK activation as detected by anti-phospho p38 MAPK antibody. No changes in p38 MAPK expression levels were detected as shown in Figs. 1 and 4. In vitro kinase assay using GST-ATF2 as a substrate and whole cell lysates were harvested 30 min after UVB irradiation. Both PD169316 and SB203580 were used at a concentration of $5 \mu \mathrm{M}$. Western blot analysis of the inhibitory effect of SB203580 pre-treatment $(5 \mu \mathrm{M})$ on cytochrome $c$ release in UVB $\left(60 \mathrm{~mJ} / \mathrm{cm}^{2}\right)$ irradiated $\mathrm{HaCaT}$ cells harvested at the indicated time points $\left.\boldsymbol{C}\right)$ Inhibitory effect of PD169316 on mitochondrial transmembrane potential loss after UVB. Cells were treated with $5 \mu \mathrm{M}$ PD169316 $1 \mathrm{~h}$ prior to irradiation and at the indicated time points trypsinized and incubated with DiOC $_{6}$ as described under Materials and Methods. Graph shows results from a representative experiment. 
Fig. 7

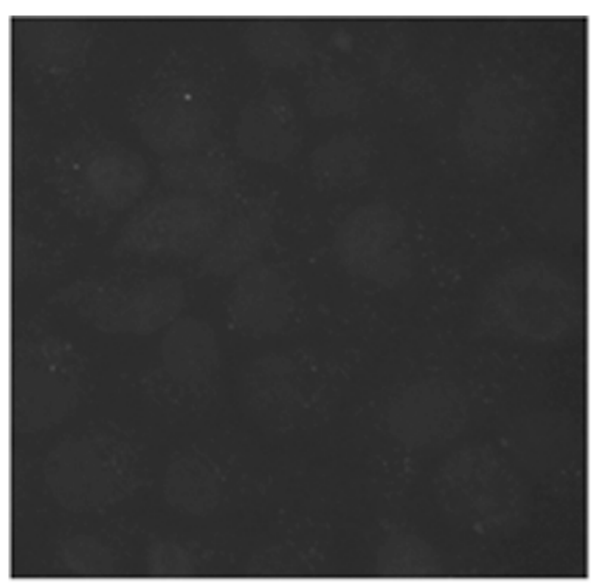

HaCaT-DRp38 untreated

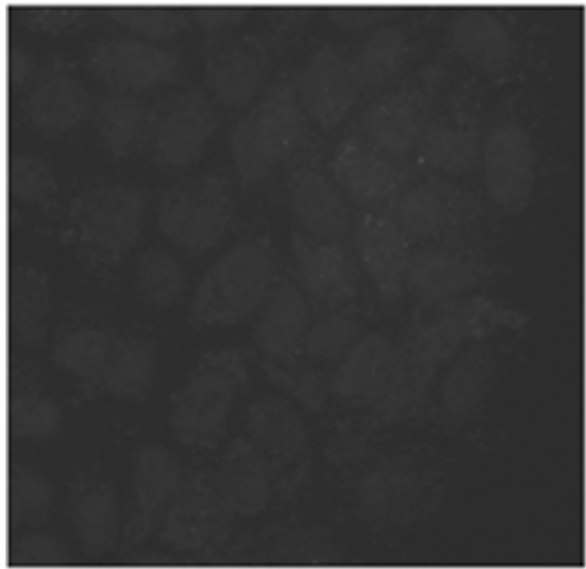

HaCaT-EV untreated

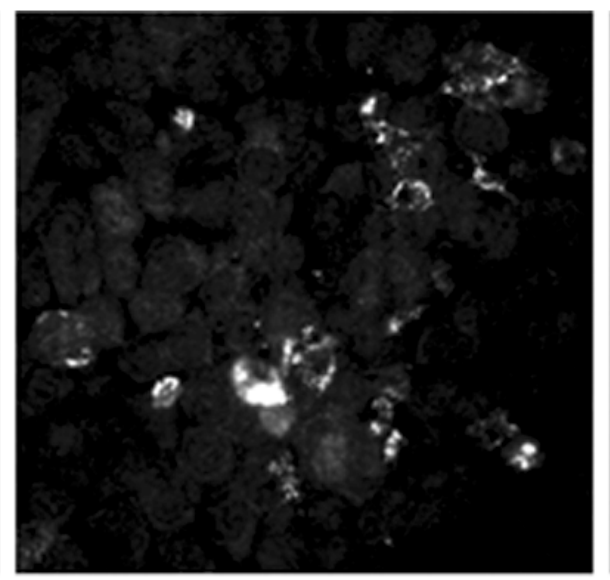

HaCaT-DRp38

UVB 10h

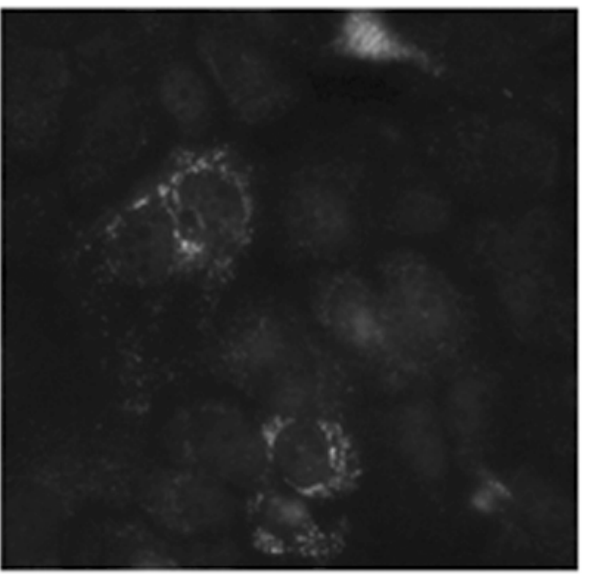

HaCaT-EV UVB 10h

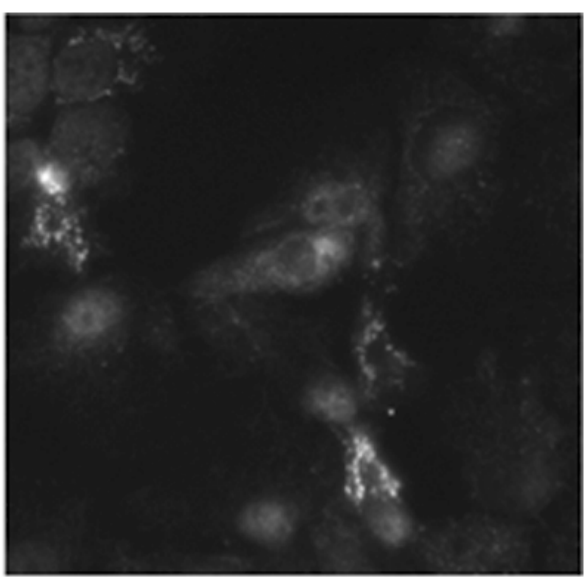

HaCaT-DRp38

UVB $10 \mathrm{~h}+\mathrm{SB}$

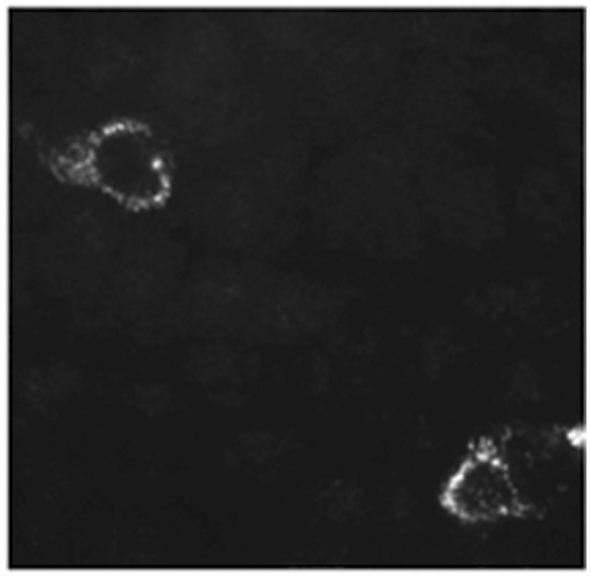

HaCaT-EV

UVB $10 \mathrm{~h}+\mathrm{SB}$

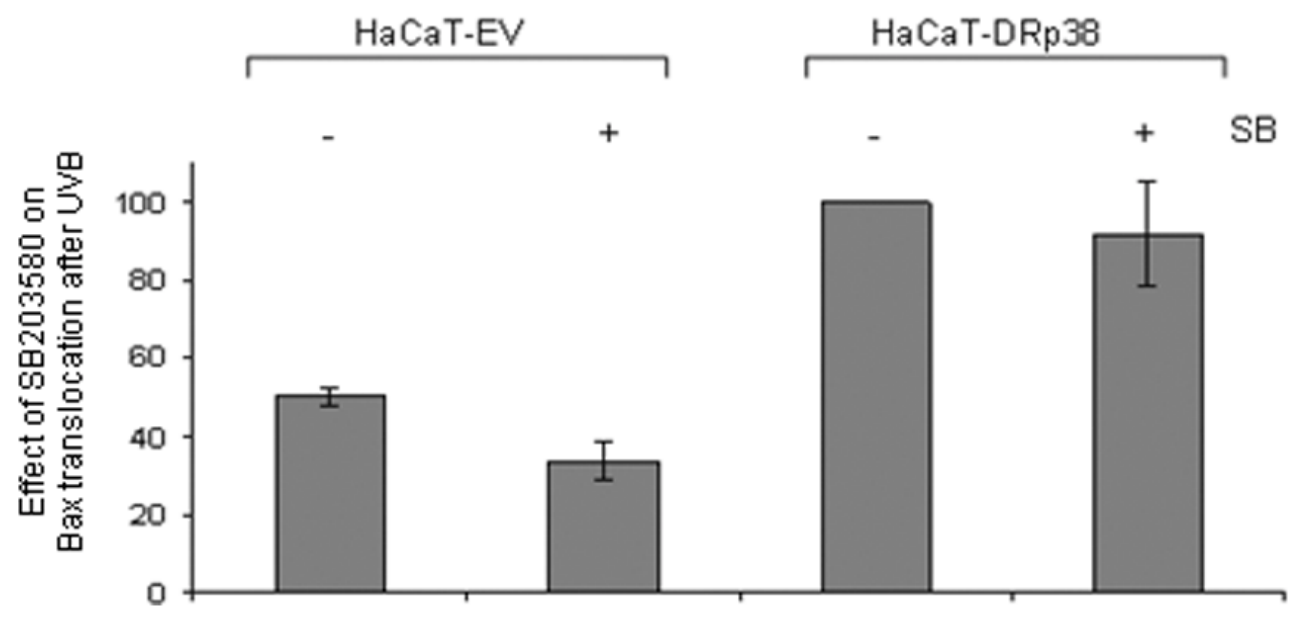


Figure 7. HaCaT cells overexpressing DRp38 $\alpha$ MAPK mutant show increased UVB-induced mitochondrial Bax translocation. Immunostaining of Bax in HaCaT-EV versus HaCaT-DRp38 $\alpha$ MAPK transfected cells. Cells were pretreated with $5 \mu \mathrm{M} \mathrm{SB} 203580,1 \mathrm{~h}$ prior to UVB irradiation $\left(20 \mathrm{~mJ} / \mathrm{cm}^{2}\right)$ or $1 \mathrm{~h}$ prior to fixation (control). Pictures were taken at $10 \mathrm{~h}$ after UVB irradiation. Graphical analysis of the SB203580 effect on Bax translocation in the HaCaTDRp38 $\alpha$ MAPK expressing cells (taken as 100\%) was compared with mock-transfected cells. Error bars represent SD of at least three independent experiments evaluated as described in Fig. 6. 
Fig. 8

A

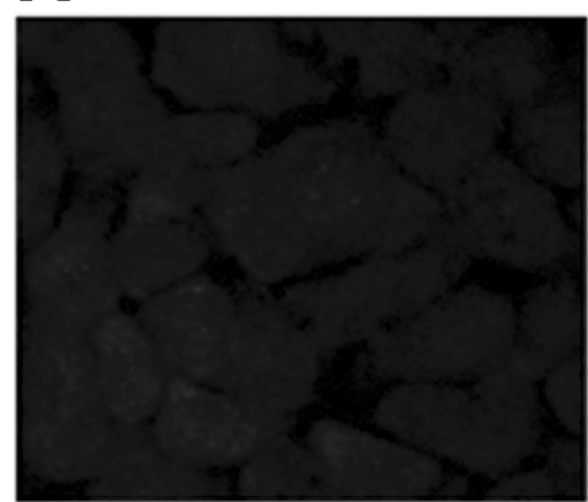

HaCaT-Bcl-2 Untreated

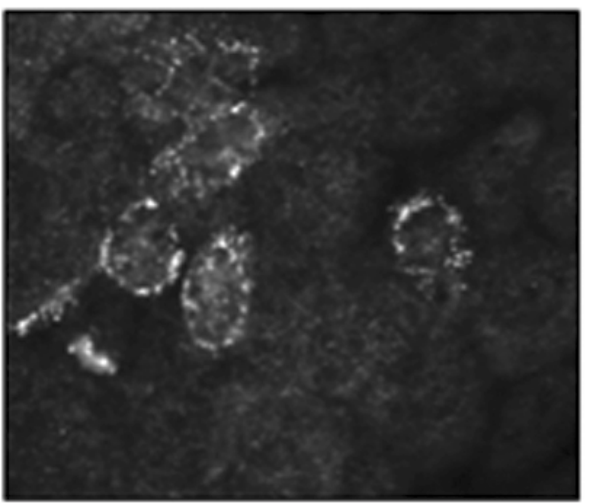

HaCaT-EV UVB 10h

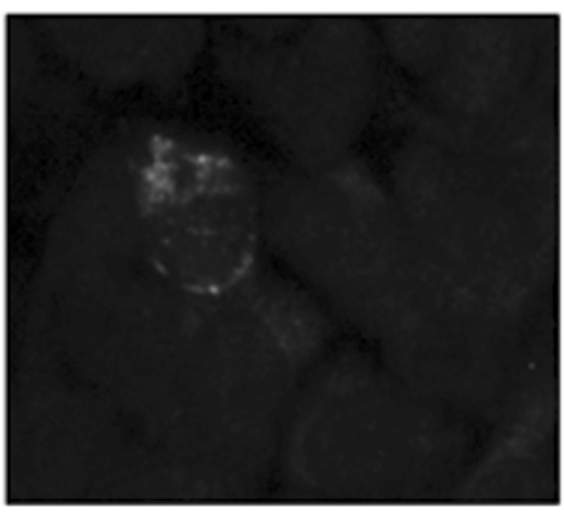

HaCaT-Bcl-2 UVB 10h

B

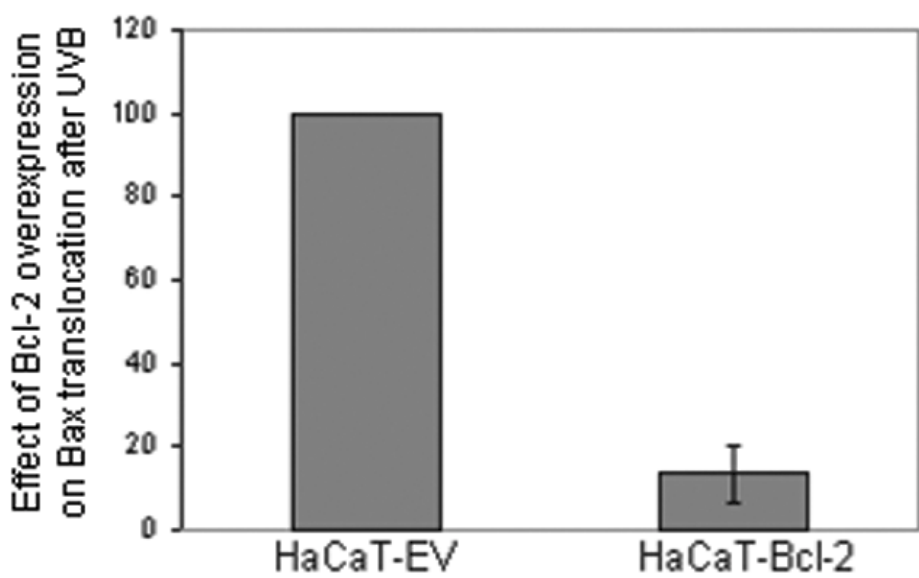

C

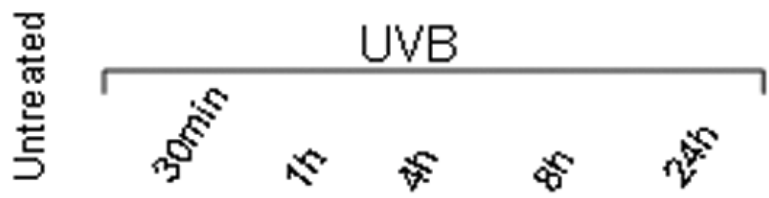

$\mathrm{HaCaT}-\mathrm{Bcl}-2$

HaCaT-EV

D

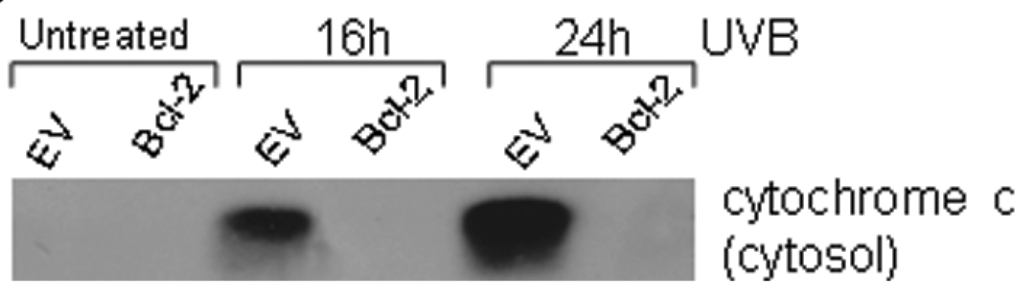


Figure 8. Bcl-2 overexpression inhibits Bax translocation and apoptosis downstream of p38 MAPK.

A) Immunostaining analysis of Bax translocation in Bcl-2 overexpressing HaCaT cells (HaCaT-Bcl-2) versus HaCaT-EV cells showing drastic reduction in the mitochondrial localization of Bax in UVB irradiated Bcl-2 overexpressing cells. Pictures were taken $10 \mathrm{~h}$ after UVB irradiation $\left(20 \mathrm{~mJ} / \mathrm{cm}^{2}\right)$. B) Quantification of the inhibitory effect of Bcl-2 on Bax translocation in UVB-irradiated cells relative to mock-transfected cells in which the percentage of Bax translocated cells is taken as $100 \%$. Error bars represent SD of at least three independent experiments. $\boldsymbol{C}$ ) Phosphorylation level of p38

MAPK in UVB-irradiated HaCaT-EV and HaCaT-Bcl-2 overexpressing cells. For phospho-p38 MAPK analysis lysates were made in HEPES containing lysis buffer. $\boldsymbol{D}$ ) Cytosolic cytochrome $c$ detection by Western blot in UVB-irradiated HaCaT-EV and HaCaT-Bcl-2 overexpressing cells after harvesting of the cells at the indicated time points. 
Fig. 9

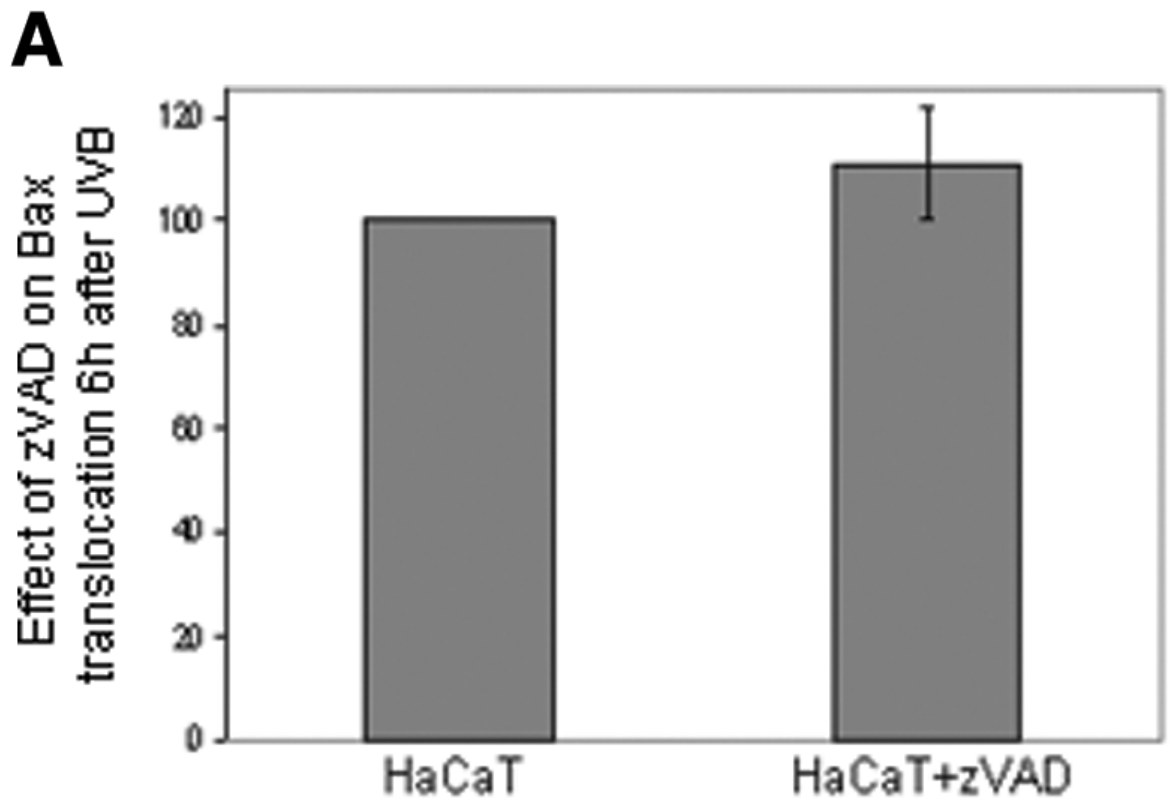

B
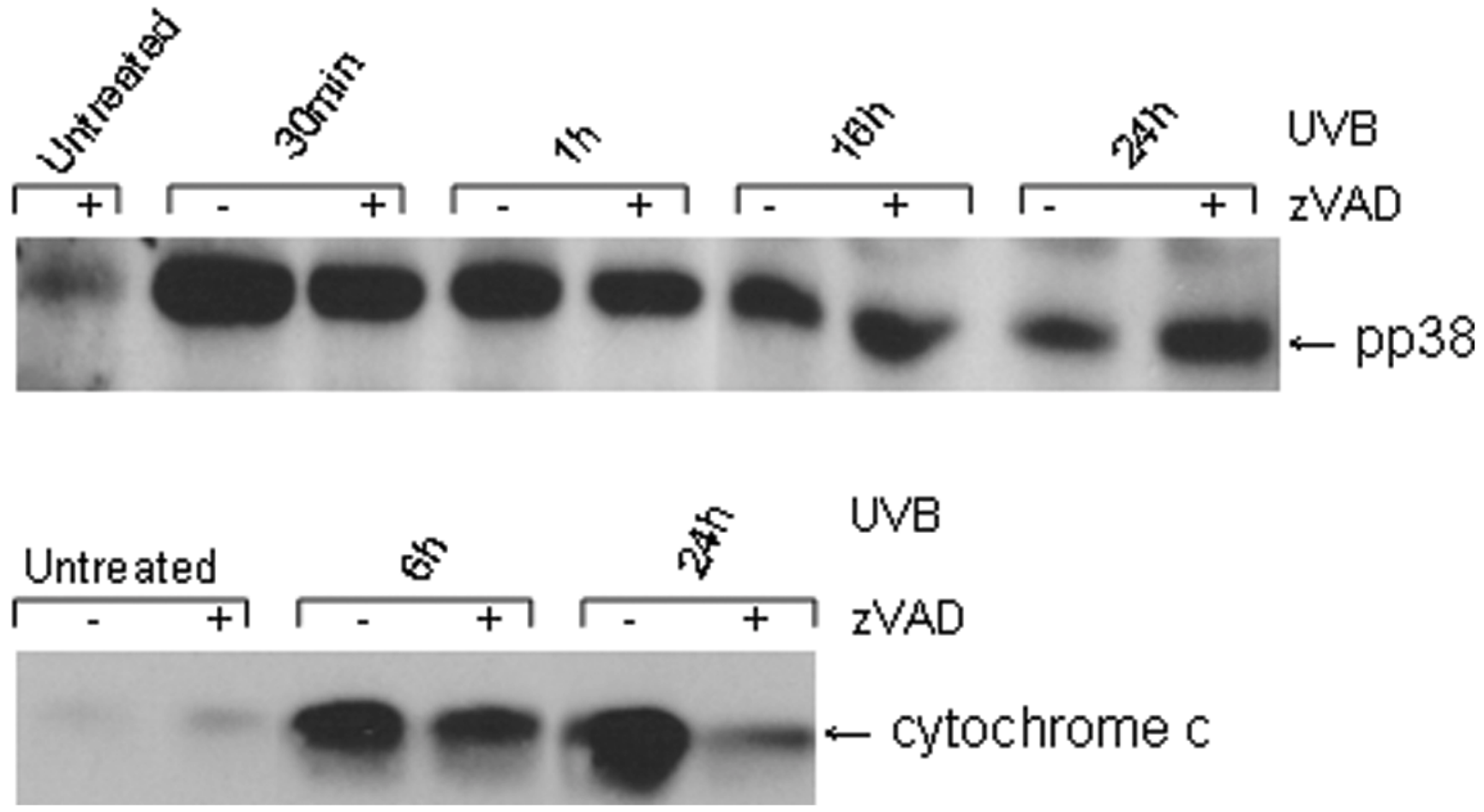

Figure 9. Caspases are not required for the translocation of Bax to the mitochondria. Effect of pretreatment of $\mathrm{HaCaT}$ cells with the pan-caspase inhibitor zVAD-fmk $(50 \mu \mathrm{M})$ on UVB-induced Bax translocation, cytochrome $c$ redistribution into the cytosol, and p38 MAPK phosphorylation. A) Bax translocation was determined in HaCaT cells $6 \mathrm{~h}$ after UVB irradiation $\left(60 \mathrm{~mJ} / \mathrm{cm}^{2}\right)$ as described under Materials and Methods. B) Western blot analysis of p38 MAPK phosphorylation and cytochrome $c$ redistribution was performed at the indicated time points post-irradiation. 
Fig. 10
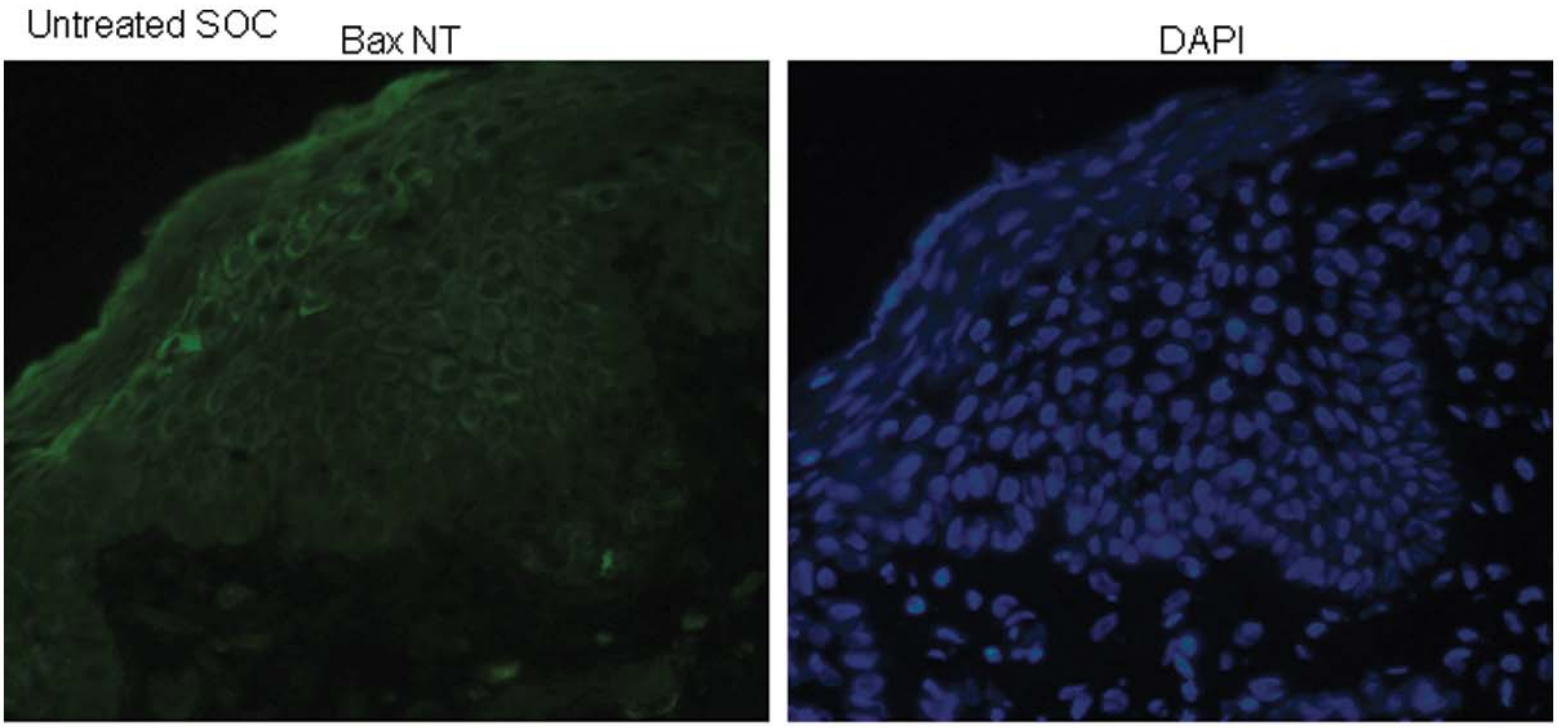

SOC UVB 16h
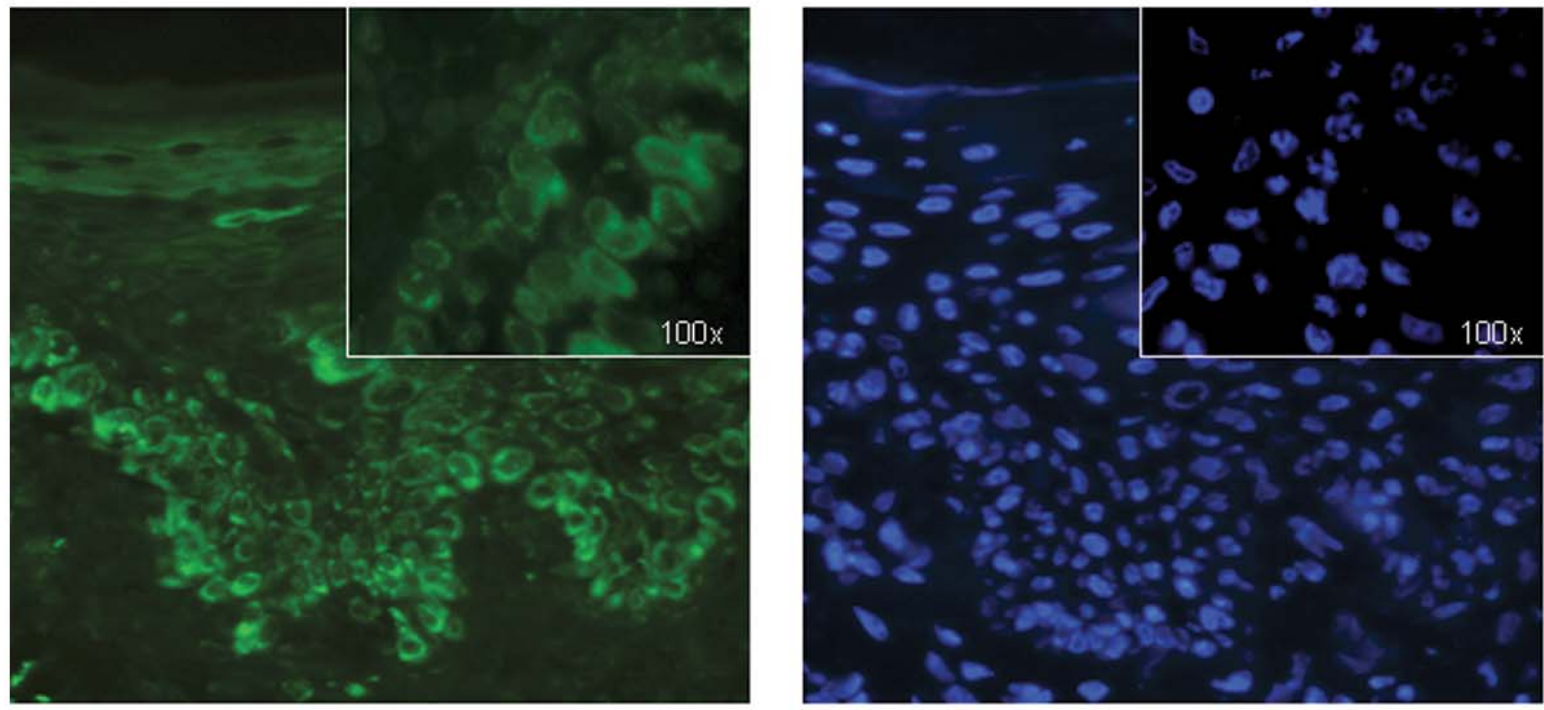

SOC UVB $16 h+P D$
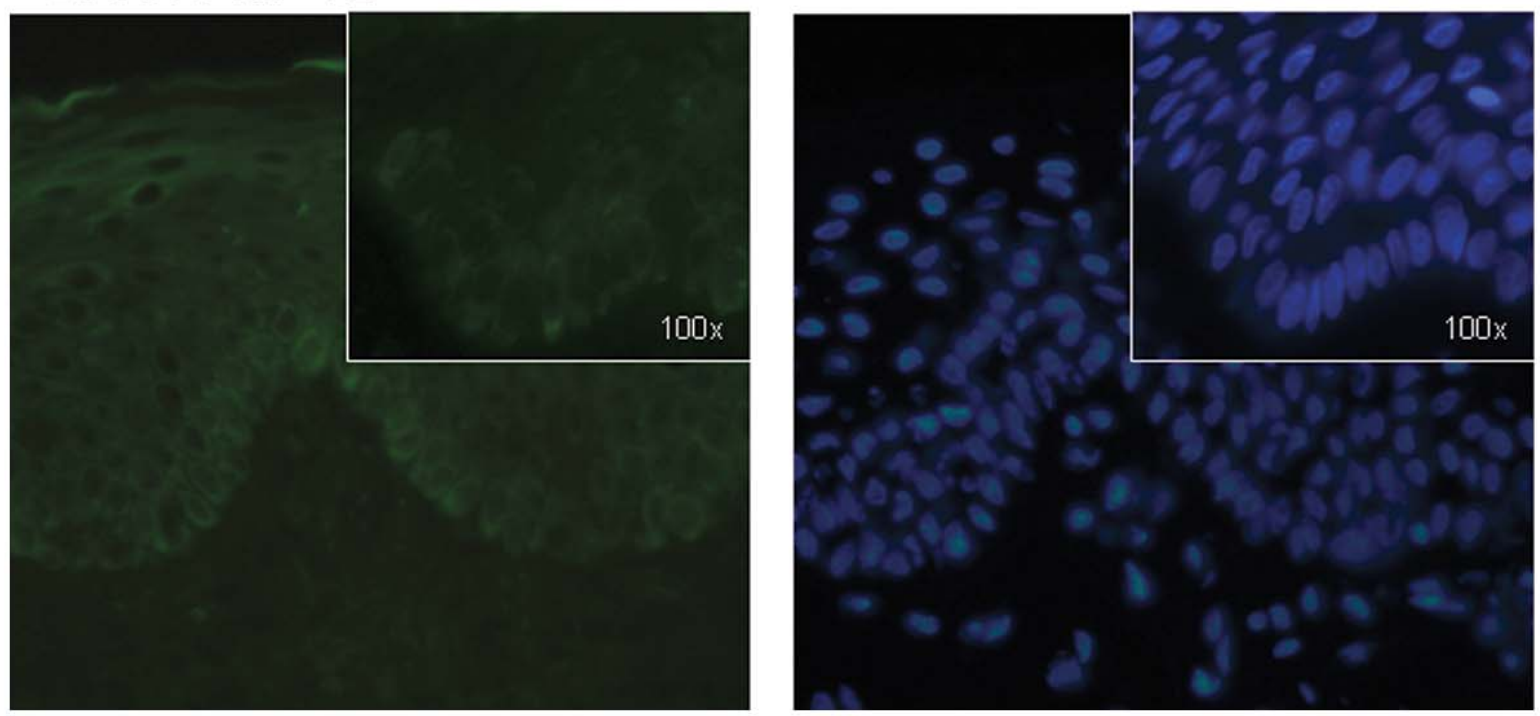

Page 31 of 33 
Figure 10. UVB-induced Bax translocation and apoptosis in normal epidermis is reduced when p38 MAPK is blocked by PD169316. Skin organ cultures (SOC) were pretreated with $20 \mu \mathrm{M}$ PD169316 $2 \mathrm{~h}$ prior to UVB irradiation. At $16 \mathrm{~h}$ after UVB $\left(300 \mathrm{~mJ} / \mathrm{cm}^{2}\right)$, the SOC were fixed and processed for immunostaining with anti-active Bax antibody as described under Materials and Methods. Images taken with a fluorescence microscope show a clear reduction of Bax translocated cells (green panels) and cells with nuclear condensation (DAPI staining, blue panels) in UVB irradiated SOC that were incubated with PD169316 prior to irradiation compared with nontreated irradiated SOC. 
Fig. 11

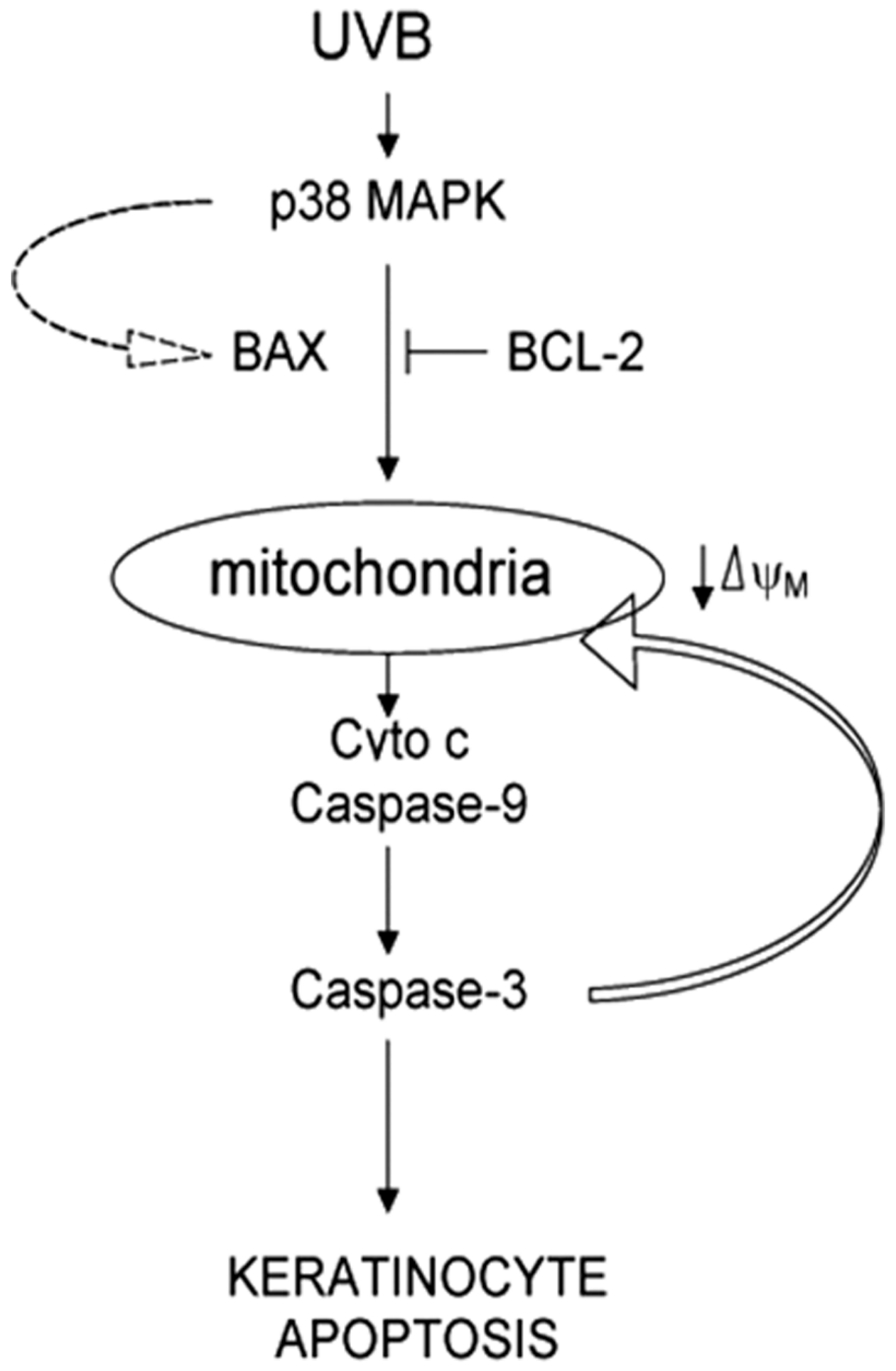

Figure 11. Activation of p38 MAPK is an important initiating signal of the mitochondrial death pathway induced by UVB. Activation of the p38 MAPK-signal by UVB mediates the conformational change of pro-apoptotic Bax and causes its translocation to the mitochondrial membrane and subsequent release of cytochrome $c$. This signaling pathway is inhibited by Bcl-2. Cytosolic cytochrome $c$ will activate the caspase cascade that feeds back to mitochondria (e.g., loss of transmembrane potential) and results in full-blown cell death. 